\title{
Is long-term autogenous shrinkage a creep phenomenon induced by capillary effects due to self-desiccation?
}

\author{
Abudushalamu Aili ${ }^{\mathrm{a}}$, Matthieu Vandamme ${ }^{\mathrm{b}, *}$, Jean-Michel Torrenti $^{\mathrm{c}}$, Benoit \\ Masson $^{\mathrm{d}}$ \\ ${ }^{a}$ Université Paris-Est, Laboratoire Navier (UMR 8205), CNRS, École des Ponts \\ ParisTech, IFSTTAR, F-77455 Marne-la-Vallée, France \\ ${ }^{b}$ Université Paris-Est, Laboratoire Navier (UMR 8205), CNRS, ENPC, IFSTTAR, \\ F-77455 Marne-la-Vallée, France \\ ${ }^{c}$ Université Paris-Est, IFSTTAR, 14 Boulevard Newton, F-77420 Champs-sur-Marne, \\ France \\ ${ }^{d}$ EDF-DIN-SEPTEN, Division GS - Groupe Génie Civil, 12-14 Avenue Dutriévoz, \\ F-69628, Villeurbanne, France
}

\section{Abstract}

Long-term shrinkage and creep of concrete can impact the lifetime of concrete structures. Basic creep of cementitious materials is now known to be non-asymptotic and evolve logarithmically with time at large times. However, the long-term kinetics of autogenous shrinkage is not systematically analyzed. Here we first aim at finding out how autogenous shrinkage evolves with time at long term. We analyze all experimental data available in the literature and find that autogenous shrinkage evolves logarithmically with respect to time at long term, like basic creep. Then, by considering concrete as a multiscale material, we obtain the bulk creep modulus of the calcium silicate hydrate gel. In the end, we show that the kinetics of long-term autogenous shrinkage can be a viscoelastic response to self-desiccation by comparing the mechanical stress that should be applied to explain this long-

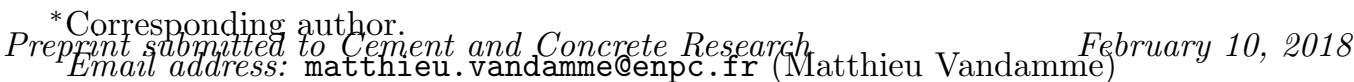


term kinetics of autogenous shrinkage with the capillary force due to selfdesiccation.

Keywords: Concrete (E), Creep (C), Shrinkage (C), Humidity (A), Self-desiccation

\section{Introduction}

Time-dependent behavior (i.e., creep and shrinkage) of cementitious materials has been studied for more than half a century. In most shrinkage-creep models $[1,2,3]$ and engineering design codes $[4,5,6]$, the time-dependent strain is decomposed into four components: autogenous shrinkage, basic creep, drying shrinkage and drying creep. In this present work, we focus only on autogenous shrinkage and basic creep, i.e., on time-dependent deformations of a sealed sample, for which drying is not involved.

Both autogenous shrinkage and basic creep are time-dependent strains that are measured on specimens that do not exchange water with their surroundings. Such condition is achieved either by sealing the sample (e.g., [7]), or by controlling the relative humidity of the environment to the same relative humidity as that of the sample (e.g., [8]). For characterization of timedependent behavior of cementitious materials under such condition, usually two specimens are needed: one reference specimen which is not loaded mechanically and another specimen which is loaded mechanically. The timedependent strain of the reference specimen is called autogenous shrinkage. Basic creep is obtained by subtracting the time-dependent strain of the refer- 
ence specimen from the time-dependent strain of the loaded specimen. Basic creep is the time-dependent strain only due to the mechanical load.

For compressive stresses below $40 \%$ of the compressive strength, the basic creep of concrete is non-asymptotic and evolves logarithmically with time at large times $[9,10,11,12]$. By analyzing the viscoelastic Poisson's ratio, Aili et al. [13] showed that even the volumetric basic creep of concrete is nonasymptotic. Microindentations (e.g., [14] and [15]) and nanoindentations [16] showed that the basic creep of cement paste and of C-S-H gel evolves logarithmically with time after a transient period.

In contrast, autogenous shrinkage is sometimes assumed to be asymptotic $[4,6,3]$, while some experimental data (e.g. $[7,17,18,19])$ show that autogenous shrinkage evolves logarithmically over time in the long term. For what concerns its physical origin, many consider that autogenous shrinkage is caused by the capillary depression due to self-desiccation [20, 21, 22, 23, 24, 25, 26, 27, 28]. However, recently, Ulm and Pellenq [29], Abuhaikal [30] and Abuhaikal et al. [31] attributed the autogenous shrinkage to eigenstresses that are developed in the solid skeleton during hydration. Both mechanisms are likely to play a role, but maybe in a magnitude that depends on the age of the material: the effect of eigenstresses is indeed expected to be significant in particularly at early ages, when hydration evolves significantly over time. For what concerns the modeling of autogenous shrinkage, several authors $[21,23,24,27]$ considered autogenous shrinkage as the elastic strain under the action of capillary forces induced by self-desiccation, while others 
$[20,22,25,26,28,32,33]$ suggested that autogenous shrinkage is the viscoelastic response of cement-based materials to the capillary forces. However, modeling autogenous shrinkage as an elastic response to self-desiccation can capture only asymptotic evolution of autogenous shrinkage at long term as self-desiccation stops at a certain time. In this work, we aim at shedding some light on this physical origin, by starting from an exhaustive analysis of data from the literature.

In the first part, we perform an exhaustive analysis of autogenous shrinkage and basic creep data from the literature. Then, by considering concrete as a multi-scale material, we use micromechanics to identify a long-term creep property of the calcium silicate hydrates (C-S-H) gel. In the third part, we discuss if the kinetics of long-term autogenous shrinkage can be explained as a creep phenomenon under the action of capillary forces caused by self-desiccation. To do so, we compare the magnitude of in-pore stresses necessary to retrieve the measured long-term creep kinetics of autogenous shrinkage with that of capillary forces.

\section{Analysis of autogenous shrinkage and basic creep data}

This section is devoted to analyze experimental data from the literature and study the long-term evolution of autogenous shrinkage and basic creep.

\subsection{Autogenous shrinkage}

We selected autogenous shrinkage data from the comprehensive database on concrete creep and shrinkage [34] compiled by Prof. Bažant and his col- 
laborators. The selection procedure is the following:

1. From the database of Northwestern University, we extracted the tests on concretes and cement pastes made from ordinary Portland cement (i.e., type CEM I according to Eurocode 2, or type I to type V according to ASTM standards) without silica fume, fly ash, filler, or slag.

2. From the extracted tests, we selected only the tests in which the measurement lasted at least until the age of 90 days.

3. We selected, from the above tests, only the tests performed at a temperature between $20^{\circ} \mathrm{C}$ and $30^{\circ} \mathrm{C}$.

In the end, we selected 45 tests in total from the database, among which 29 were performed on concrete and 16 on cement paste.

Figure 1a shows the evolution of autogenous shrinkage over time for three representative tests. At large times, autogenous shrinkage evolves linearly with the logarithm of time. Such logarithmic evolution was in fact observed for all concretes and cement pastes prepared at a water-to-cement mass ratio below 0.5. Among the above 45 tests, mass loss of the sample over the experiment was measured only in [17] and amounted to about $0.03 \%$ at the age of 240 days. For all other tests, mass was not measured over time, such that the effectiveness of the sealing during the measurement of autogenous shrinkage cannot be assessed and we cannot rule out some loss of water during the test. Hence, part of the measured autogenous shrinkage might be attributed to drying. However, an uncontrolled loss of water over time 


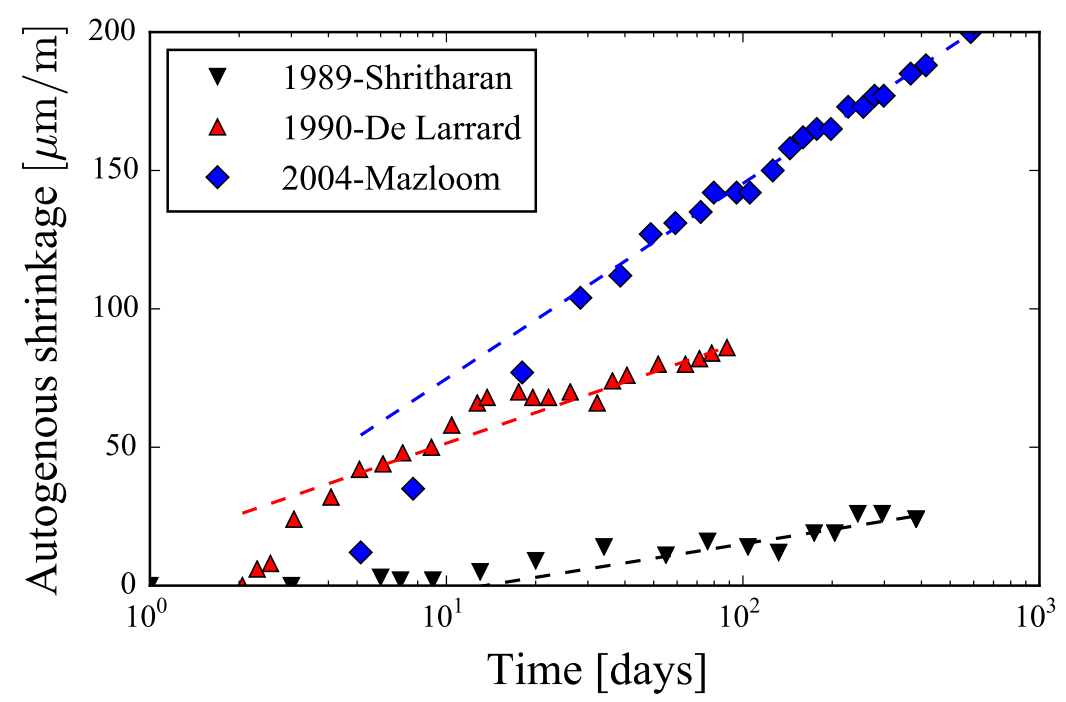

(a)

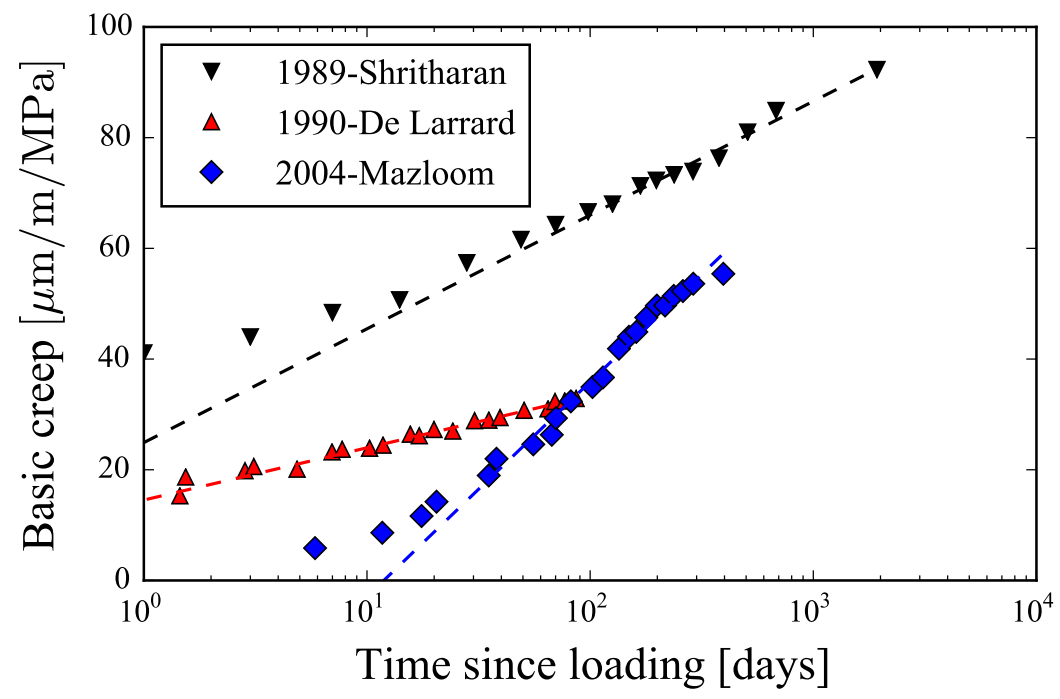

(b)

Figure 1: (a) Example of autogenous shrinkage data; (b) Example of basic creep data. Data from $[35,7,17]$ 
could not lead to a consistent logarithmic evolution of autogenous shrinkage for all the tests extracted from the database, and we therefore attribute this evolution to autogenous shrinkage. As the effectiveness of sealing is an important feature of autogenous shrinkage or basic creep measurements, a good practice would be to measure the mass of the sample before and after testing. Monitoring of the mass loss of sample could be improved, especially in autogenous shrinkage test, by measuring the mass of sample during the whole test.

For all selected tests we fitted the following empirical relation:

$$
\varepsilon_{s h}(t)=\alpha_{s h} \log \left(\frac{t}{\tau_{0}}\right)+\beta_{s h},
$$

to all data points obtained at the age of more than 28 days. In Eq. $1, \varepsilon_{s h}$ is the autogenous shrinkage strain, $\alpha_{s h}$ is the slope of autogenous shrinkage displayed versus $\log (t), t$ is the age of concrete and $\tau_{0}=1$ day is a reference time. Table 1 summarizes the origin of the data, the mix design properties of the tested concretes, and the fitted parameter $\alpha_{s h}$. For the sake of clarity, only the data related to the three tests displayed in Fig. 1a are given in Tab. 2. For the data related to all 45 tests used in this study, see Tabs. A.4 and A.5 in Appendix A.

If the kinetics of long-term autogenous shrinkage can be explained as a creep phenomenon under the action of capillary forces that would induce a representative stress $\Sigma_{h}$, this representative stress should be related to the 


\begin{tabular}{|l||l|l|l|l|l|}
\hline Author & File $^{1}$ & $\mathrm{w} / \mathrm{c}^{2}$ & $\mathrm{a} / \mathrm{c}^{3}$ & $\mathrm{c}^{4}$ & $\alpha_{s h}{ }^{6}$ \\
\hline \hline Shritharan (1989) & e_079_06 & 0.47 & 5.09 & 393 & 7.51 \\
\hline De Larrard (1990) & A_022_05 & 0.35 & 3.96 & 450 & 15.96 \\
\hline Mazloom (2004) & A_031_02 & 0.35 & 3.70 & 500 & 30.64 \\
\hline
\end{tabular}

Table 1: Extract of autogenous shrinkage data. ${ }^{1}$ File corresponds to the file number in the database compiled by Prof. Bažant and his collaborators [34]; ${ }^{2} \mathrm{w} / \mathrm{c}$ : water-to-cement ratio; ${ }^{3} \mathrm{a} / \mathrm{c}$ : aggregate-to-cement mass ratio; ${ }^{4} \mathrm{c}$ : cement per volume of mixture $\left[\mathrm{kg} / \mathrm{m}^{3}\right] ;{ }^{5} \alpha_{s h}$ : Fitted parameter in Eq. 1 $[\mu \mathrm{m} / \mathrm{m}]$.

fitted parameter $\alpha_{s h}$ through:

$$
\Sigma_{h}=3 \alpha_{s h} C_{c}^{K}
$$

where $C_{c}^{K}$ is the bulk creep modulus of the tested concrete or cement paste, which is defined, in a creep test under the stress $\sigma_{0}$, as the asymptotic value of $\sigma_{0} /(t d \varepsilon / d t)$ in the long term [36]. Hence, in order to back-calculate the stress $\Sigma_{h}$ that would be necessary to explain the long-term kinetics of autogenous shrinkage as a creep phenomenon, we first need the bulk creep modulus $C_{c}^{K}$ of each concrete or cement paste. In the next section, we analyze basic creep data to obtain this parameter. On all the samples used for the 45 tests of autogenous shrinkage analyzed, only 5 measurements of basic creep were performed. To back-calculate creep properties of C-S-H, instead of limiting ourselves to the analysis of those 5 tests only, in the next section we will analyze a larger number of basic creep tests extracted from the database of Northwestern University. 


\subsection{Basic creep}

We selected basic creep data also from the comprehensive database on concrete creep and shrinkage [34] compiled by Prof. Bažant and his collaborators. We selected all basic creep data that satisfy the following criteria:

1. From the database of Northwestern University, we extracted the tests on concretes and cement pastes made from ordinary Portland cement (i.e., type CEM I according to Eurocode 2, or type I to type V according to ASTM) without silica fume, fly ash, filler, or slag.

2. From the extracted tests, we selected only the tests for which the measurement after 5 times the age at loading lasted for at least a decade in logarithmic scale.

3. We selected, from the above tests, only the tests performed at a temperature between $20^{\circ} \mathrm{C}$ and $30^{\circ} \mathrm{C}$.

4. We selected, from the above tests, only the tests in which the applied stress did not exceed $40 \%$ of the compressive strength.

With these criteria, we selected in total 59 tests from the database. All those 59 tests were in fact performed on concrete samples.

Figure 1b displays the evolution of basic creep over time for three representative tests. At large times, the evolution of basic creep is logarithmic with time for all selected tests. Hence, for all selected tests, on the part of the data going from the time equal to 5 times the age of loading till the end of the test, we fitted the following empirical relation: 


\begin{tabular}{|l||l|l|l|l|l|l|}
\hline Author & File $^{1}$ & $\mathrm{w} / \mathrm{c}^{2}$ & $\mathrm{a} / \mathrm{c}^{3}$ & $\mathrm{c}^{4}$ & $\mathrm{t}_{0}{ }^{5}$ & $1 / C_{c}^{E 6}$ \\
\hline \hline Shritharan (1989) & c_079_08 & 0.47 & 5.09 & 390 & 14 & 8.93 \\
\hline De Larrard (1990) & D_022_05 & 0.35 & 3.96 & 450 & 3 & 4.10 \\
\hline Mazloom (2004) & D_031_02 & 0.35 & 3.70 & 500 & 7 & 16.86 \\
\hline
\end{tabular}

Table 2: Extract of basic creep data. ${ }^{1}$ File corresponds to the file number in the database compiled by Prof. Bažant and his collaborators [34]; ${ }^{2} \mathrm{w} / \mathrm{c}$ : water-to-cement ratio; ${ }^{3} \mathrm{a} / \mathrm{c}$ : aggregate-to-cement mass ratio; ${ }^{4} \mathrm{c}$ : cement per volume of mixture $\left[\mathrm{kg} / \mathrm{m}^{3}\right] ;{ }^{5} \mathrm{t}_{0}$ : loading age [days]; ${ }^{6} 1 / C_{c}^{E}$ : Fitted parameter in Eq. $3[\mu \mathrm{m} / \mathrm{m} / \mathrm{MPa}]$.

$$
\varepsilon_{c r}(t)=\frac{1}{C_{c}^{E}} \log \left(\frac{t}{\tau_{0}}\right)+\beta_{c r},
$$

where $\varepsilon_{c r}$ is the specific basic creep strain, $1 / C_{c}^{E}$ is the slope of basic creep displayed versus $\log (t), t$ is time since loading and $\tau_{0}=1$ day is a reference time. The parameter $C_{c}^{E}$ is called the uniaxial creep modulus of concrete. Table 2 summarizes the origin of the data, the mix design properties of the tested concretes, the age at loading, and the fitted parameter $1 / C_{c}^{E}$. For the sake of clarity, only the data related to the three experiments displayed in Fig. $1 \mathrm{~b}$ are given in Tab. 2. For the data related to all 59 tests used in this study, see Tabs. B.6 and B.7 in Appendix B.

In conclusion, we confirmed that basic creep evolves logarithmically with respect to time at long term. Our analysis of an exhaustive set of data shows that autogenous shrinkage also evolves logarithmically with respect to time at long term. 


\section{Downscaling of creep compliance from the scale of concrete to the scale of the C-S-H gel}

The objective of this section is to estimate the long-term creep properties of the C-S-H gel from the basic creep data on concrete presented in section 2.2. As the creep of concrete evolves logarithmically with respect to time in the long term, we can express the bulk creep compliance $J_{c}^{K}$ of concrete as $J_{c}^{K}=1 / K_{c}^{0}+1 / C_{c}^{K} \log \left(1+t / \tau_{c}\right)$, where $C_{c}^{K}$ is the bulk creep modulus that characterizes the-long term kinetics of bulk creep.

Aili et al. [13] showed that the viscoelastic Poisson's ratio $\nu_{c}$ of concrete remains quite constant and comprised between 0.15 and 0.2 for mature concretes. Hence, we consider the viscoelastic Poisson's ratio $\nu_{c}$ of concrete to be constant and equal to 0.2. Then, following the same procedure as in Appendix B of [16], we obtain the relation between the bulk creep modulus $C_{c}^{K}$ and the uniaxial creep modulus $C_{c}^{E}$ :

$$
C_{c}^{K}=\frac{C_{c}^{E}}{3\left(1-2 \nu_{c}\right)} .
$$

The objective is now to relate this bulk creep modulus $C_{c}^{K}$ of concrete to the bulk creep modulus $C_{\text {gel }}^{K}$ of the C-S-H gel.

We first present the multi-scale scheme of concrete that we are going to use in this article. Then, we derive some theoretical results by adapting elastic homogenization schemes to the viscoelastic case via the correspondence principle [37]. In the end, we apply the derived equations to relate the bulk 
creep modulus $C_{c}^{K}$ of concrete to the bulk creep modulus $C_{g e l}^{K}$ of the C-S-H gel.

\subsection{Multiscale model for concrete}

Concrete can be regarded as a multiscale composite material at three different scales, which are displayed in Fig. 2:

- At the largest scale of concrete (see Fig. 2a), the aggregates are considered as spherical inclusions that do not creep and are embedded into a matrix made of cement paste, which creeps.

- At a scale below, i.e., at the scale of the cement paste (see Fig. 2b), portlandite, aluminate phases (i.e., ettringite AFt and mono-sulfoaluminate AFm phases) and the unhydrated clinker are considered as spherical inclusions that do not creep and are embedded into a matrix made of a mixture of $\mathrm{C}-\mathrm{S}-\mathrm{H}$ with capillary pores. This mixture is considered to creep.

- At another scale below (see Fig. 2c), the mixture of C-S-H with capillary pores is considered to be a matrix of C-S-H gel (which contains the gel porosity) which surrounds spherical capillary pores.

As explained before, according to the findings of Aili et al. [13], here we consider the viscoelastic Poisson's ratio of concrete (Fig. 2a) equal to 0.2. As shown by Aili et al. (Eqs. 14 and 15 in [13]), this assumption implies that for the multiscale model here considered, we can also consider the viscoelastic 


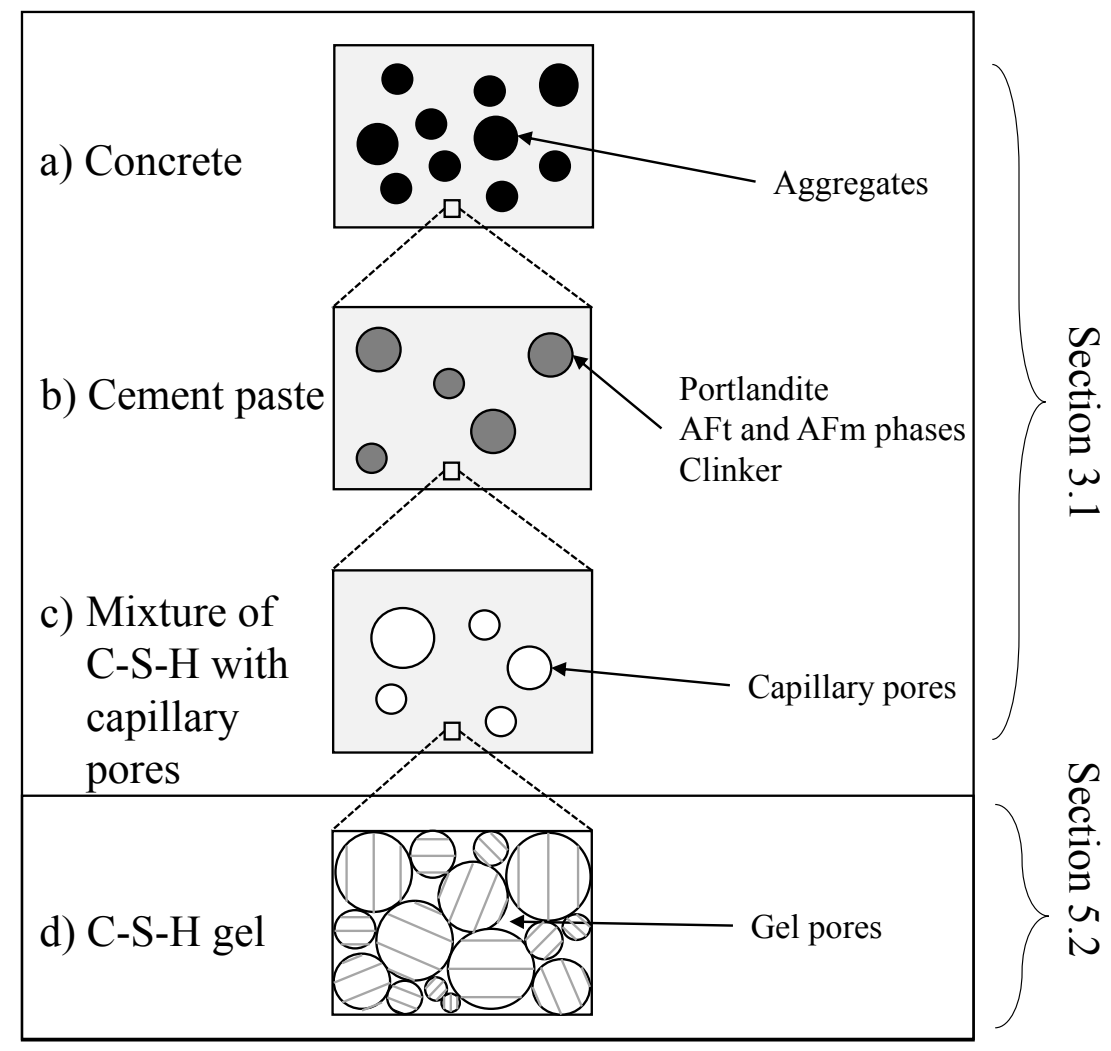

Figure 2: Multiscale structure of concrete: (a) Concrete as a matrix of cement paste embedding aggregates, (b) cement paste as portlandite, AFt and AFm phases and unhydrated clinker embedded into a matrix made of a mixture of C-S-H with capillary pores, (c) mixture of C-S-H with capillary pores as a matrix of C-S-H gel surrounding capillary porosity, and (d) C-S-H gel as a mixture of C-S-H particles and gel pores. The scales (a) (b) (c) are considered in Sec. 3.1 for the downscaling of the creep modulus, while the scale $(d)$ is considered in Sec. 5.2 for estimating the Biot coefficient of the mixture of C-S-H gel with capillary pores.

Poisson's ratio of cement paste (Fig. 2b), of the mixture of C-S-H gel and

capillary pores (Fig. 2c), and of the C-S-H gel as constant and equal to 0.2. 


\subsection{Theoretical derivation}

We consider a composite made of a matrix that embeds spherical inclusions. Given the microstructure, we employ the Mori-Tanaka scheme [38, 39] to calculate the properties of the composite as a function of the properties of each phase (i.e., of the matrix and the inclusions). Note that the Mori-Tanaka scheme is valid even at high volume fractions of inclusions [40, 41, 42, 43, 44]. The interface between inclusions and matrix is considered to be perfectly adhesive. The viscoelastic Poisson's ratio $\nu_{m}$ of the matrix is constant and equal to 0.2. Applying the correspondence principle [37] to the elastic Mori-Tanaka homogenization scheme, making use of the fact that $\nu_{m}=0.2$, replacing the elastic parameters by the $s$-multiplied Laplace transform of their corresponding viscoelastic operator, we obtain the viscoelastic homogenization scheme in the Laplace domain:

$$
\widehat{K_{c o m}}=\frac{\widehat{K_{m}}\left(1-f_{i}\right)+\widehat{K}_{i}\left(1+f_{i}\right)}{\widehat{K_{m}}\left(1+f_{i}\right)+\widehat{K}_{i}\left(1-f_{i}\right)},
$$

where $f_{i}$ is the volume fraction of inclusions; $K_{m}, K_{i}$ and $K_{c o m}$ are the viscoelastic bulk relaxation modulus of the matrix, of the inclusion and of the composite, respectively; $\widehat{g}$ is the the Laplace transform of the function $g$.

These bulk relaxation moduli $K_{j}$ are related to bulk creep compliances $J_{j}^{K}$ through:

$$
s \widehat{J_{j}^{K}}=\frac{1}{s \widehat{K}_{j}}
$$


where $s$ is the Laplace variable, $j=m, i$, com represents matrix, inclusion and composite, respectively.

We suppose that the bulk creep compliances $J_{j}^{K}$ evolve logarithmically with respect to time at large times and can be expressed as $J_{j}^{K}=\left(1 / K_{j}^{0}\right)+$ $\left(1 / C_{j}^{K}\right) \log \left(1+t / \tau_{j}\right)$, where $j=m, i$, com and $C_{j}^{K}$ is the bulk creep modulus. By using the final value theorem [45] and the Laplace transform of a derivative, we obtain the following relation between the bulk creep modulus $C_{j}^{K}$ and the Laplace transform $\widehat{J_{j}^{K}}$ of the bulk creep compliance:

$$
\begin{aligned}
\frac{1}{C_{j}^{K}} & =\lim _{t \rightarrow \infty} t \dot{J_{j}^{K}}=\lim _{s \rightarrow 0} s \widehat{\left(t \dot{J_{j}^{K}}\right)}=\lim _{s \rightarrow 0}\left(-s \frac{d}{d s} \widehat{\left(\widehat{J_{j}^{K}}\right)}\right) \\
& =\lim _{s \rightarrow 0}\left(-s \frac{d}{d s}\left(s \widehat{\left(J_{j}^{K}\right)}-\left.J_{j}^{K}\right|_{t=0}\right)\right)=\lim _{s \rightarrow 0}\left(-s \frac{d}{d s}\left(s \widehat{\left(J_{j}^{K}\right)}\right)\right),
\end{aligned}
$$

where $\dot{g}$ is the derivative of the function $g$ with respect to time. Equation 7 means that $d\left(s \widehat{J_{j}^{K}}\right) / d s$ can be approximated by $-1 / s C_{j}^{K}$ for small $s$, from which follows that $\widehat{J_{j}^{K}}$ can approximated by $-\log (s) / C_{j}^{K} s$ for small $s$ :

$$
\widehat{J_{j}^{K}} \approx-\log (s) / C_{j}^{K} s, \text { for } s \rightarrow 0
$$

${ }_{254}$ Using the final value theorem [45], letting $s \rightarrow 0$ in Eq. 5 and combining the result with Eqs. 6 and 8, we obtain:

$$
C_{c o m}^{K}=\frac{C_{m}^{K}\left(1-f_{i}\right)+C_{i}^{K}\left(1+f_{i}\right)}{C_{m}^{K}\left(1+f_{i}\right)+C_{i}^{K}\left(1-f_{i}\right)} C_{m}^{K}
$$


which makes it possible to relate the bulk creep modulus $C_{c o m}^{K}$ of the composite to that of its constituents.

We consider the following two cases:

- Case 1: Composite made of a matrix embedding non-creeping inclusions. The matrix is considered to creep logarithmically with respect to time in the long term. The long-term volumetric creep kinetics of the matrix is characterized by its creep modulus $C_{m}^{K}$. Letting $C_{m}^{K} / C_{i}^{K} \rightarrow 0$, Eq. 9 yields:

$$
C_{\text {com }}^{K}=\frac{1+f_{i}}{1-f_{i}} C_{m}^{K}
$$

- Case 2: Porous composite made of a matrix embedding spherical pores. Letting $C_{i}^{K} / C_{m}^{K} \rightarrow 0$, Eq. 9 yields:

$$
C_{c o m}^{K}=\frac{1-f_{i}}{1+f_{i}} C_{m}^{K}
$$

\subsection{From concrete to $C-S-H$ gel}

In this section, we derive a relation between the bulk creep modulus $C_{c}^{K}$ of concrete and $C_{g e l}^{K}$ of the C-S-H gel, by performing three steps of downscaling following the multi-scale scheme displayed in Fig. 2.

- To relate the bulk creep modulus $C_{c}^{K}$ of concrete to the bulk creep modulus $C_{p}^{K}$ of cement paste (Fig. 2a), we apply Eq. 10. 
- To relate the bulk creep modulus $C_{p}^{K}$ of cement paste to the bulk creep modulus $C_{m i x}^{K}$ of the mixture of C-S-H gel with capillary pores (Fig. 2b), we apply again Eq. 10.

- To relate the bulk creep modulus $C_{m i x}^{K}$ of the mixture of C-S-H gel with capillary pores to the bulk creep modulus $C_{g e l}^{K}$ of the C-S-H gel (Fig. 2c), we apply Eq. 11.

With these three steps of downscaling, we obtain:

$$
C_{c}^{K}=\left(\frac{1+f_{a}}{1-f_{a}}\right)\left(\frac{1+f_{b}}{1-f_{b}}\right)\left(\frac{1-\phi_{c}}{1+\phi_{c}}\right) C_{g e l}^{K},
$$

where $f_{a}$ is the volume fraction of aggregates (counted with respect to the volume of concrete); $f_{b}$ is the volume fraction of portlandite, $\mathrm{AFt}$ and $\mathrm{AFm}$ phases and unhydrated clinker (counted with respect to the volume of cement paste); $\phi_{c}$ is the volume fraction of the capillary porosity (counted with respect to the volume of the mixture of C-S-H gel with capillary pores).

Combining Eqs. 4 and 12, we obtain:

$$
C_{g e l}^{K}=\left(\frac{1-f_{a}}{1+f_{a}}\right)\left(\frac{1-f_{b}}{1+f_{b}}\right)\left(\frac{1+\phi_{c}}{1-\phi_{c}}\right) \frac{1}{3\left(1-2 \nu_{c}\right)} C_{c}^{E}
$$

This equation makes it possible to compute the bulk creep modulus $C_{g e l}^{K}$ of the C-S-H gel from the uniaxial creep modulus $C_{c}^{E}$ obtained from the analysis of basic creep data, as long as the microstructural parameters $f_{a}, f_{b}$, and $\phi_{c}$ are known. 
To determine the microstructural parameters $f_{a}, f_{b}$, and $\phi_{c}$, we use the following:

- The volume fraction $f_{a}$ of aggregates in concrete is computed from the mix design properties of concrete: $f_{a}=1-c / \rho_{c}-c \times w / c / \rho_{w}$, where $c$ and $w / c$ are the mass of clinker per volume of mixture and the waterto-cement mass ratio, respectively, and where $\rho_{c}=3.15 \mathrm{~g} / \mathrm{cm}^{3}$ and $\rho_{w}=1 \mathrm{~g} / \mathrm{cm}^{3}$ are the density of cement and of water, respectively.

- The volume fraction $f_{b}$ of portlandite, AFt and AFm phases and unhydrated clinker (counted with respect to the volume of the cement paste) is the sum of the volume fractions of portlandite, of AFt and AFm phases, and of unhydrated clinker. Each of them is computed by using Powers' model $[46,47]$, which considers that the volume of cement paste is composed of bulk hydrates (i.e., solid hydrates plus gel pores), unhydrated clinker, and capillary pores. As Powers et al. [46] stated, complete hydration almost never occurs in practice. Therefore, instead of the final hydration degree given by Powers' model, here we consider the long-term hydration degree $\xi^{\infty}$ of the sample to be equal to $\xi^{\infty}=1-\exp (-3.3 w / c)$ [48]. The volume fraction of bulk hydrates per unit volume of cement paste is $2.12(1-p) \xi^{\infty}$, where $p=(w / c) /\left((w / c)+\left(\rho_{w} / \rho_{c}\right)\right)$. The volume of portlandite per unit volume of bulk hydrates is estimated to be equal to $25 \%$, which is a typical value for CEM I cement pastes [49]. Hence, the volume fraction 
of portlandite (counted with respect to the volume of cement paste) is $0.53(1-p) \xi^{\infty}$. The volume fraction of AFt and AFm phases per unit volume of bulk hydrates is estimated to be equal to $15 \%$ [49], from which the volume fraction of AFt and AFm phases (counted with respect to the volume of cement paste) is $0.32(1-p) \xi^{\infty}$. The volume fraction of unhydrated clinker (still counted with respect to the volume of cement paste) is estimated also with Powers' model $[46,47]$ to be equal to $(1-p)\left(1-\xi^{\infty}\right)$. Therefore, the volume fraction $f_{b}$ of portlandite, AFt and AFm phases and unhydrated clinker (counted with respect to the volume of the cement paste) is $f_{b}=0.85(1-p) \xi^{\infty}+(1-p)\left(1-\xi^{\infty}\right)$.

- The volume fraction $\phi_{c}$ of capillary porosity with respect to the volume of the mixture of $\mathrm{C}-\mathrm{S}-\mathrm{H}$ gel with capillary pores is also computed by using Powers' model [46, 47]. The volume fraction of capillary pores counted with respect to the volume of cement paste is estimated as $p-1.12(1-p) \xi^{\infty}$. The volume fraction of the mixture of C-S-H gel with capillary pores (counted with respect to the volume of cement paste) is equal to $1-f_{b}$. Hence, the capillary porosity $\phi_{c}$ (i.e., volume fraction of the capillary pores counted with respect to the volume of the mixture of C-S-H gel with capillary pores) is equal to $\left(p-1.12(1-p) \xi^{\infty}\right) /\left(1-f_{b}\right)$.

Inserting the uniaxial creep modulus $C_{c}^{E}$ from Tab. 2 and the abovecalculated microstructural parameters $f_{a}, f_{b}$ and $\phi_{c}$ into Eq. 12, we obtain the bulk creep modulus $C_{g e l}^{K}$ of the C-S-H gel. The results are displayed 
in Fig. 3. The bulk creep modulus $C_{g e l}^{K}$ of C-S-H gel does not exhibit any specific trend with water-to-cement ratio. Its mean value is $13 \mathrm{GPa}$ and its standard deviation is $6.7 \mathrm{GPa}$. The quite large standard deviation may partly be due to the fact that creep moduli are fitted on measurements that last for extended periods of time and hence are difficult to perform, and also to the fact that creep moduli characterize a rate and are therefore quite sensitive to experimental noise.

In Fig. 3, we also display creep moduli of C-S-H gel obtained by backcalculation of microindentation creep data on cement pastes obtained by Zhang [50] and by Frech-Baronet et al. [15] at various relative humidities. Zhang [50] found that the contact creep modulus of the C-S-H gel is constant for relative humidities greater than $75 \%$. Consequently, to be consistent with the internal relative humidities observed in autogenous conditions, out of the various microindentation creep experiments performed by Zhang and by Frech-Baronet et al., we only analyzed those performed at a relative humidity larger than $75 \%$, which resulted in the analysis of 3 of Zhang's tests, and of 1 of Frech-Baronet's tests. Following the same procedure as described above, those results were downscaled to yield the bulk creep modulus of the C-S-H gel, which is displayed in Fig. 3. While creep moduli back-calculated from Frech-Baronet's results lie slightly above the range of creep moduli back-calculated from uniaxial creep experiments on concrete, creep moduli back-calculated from Zhang's results lie in that range. This agreement is consistent with the fact that indentation of cement paste has 


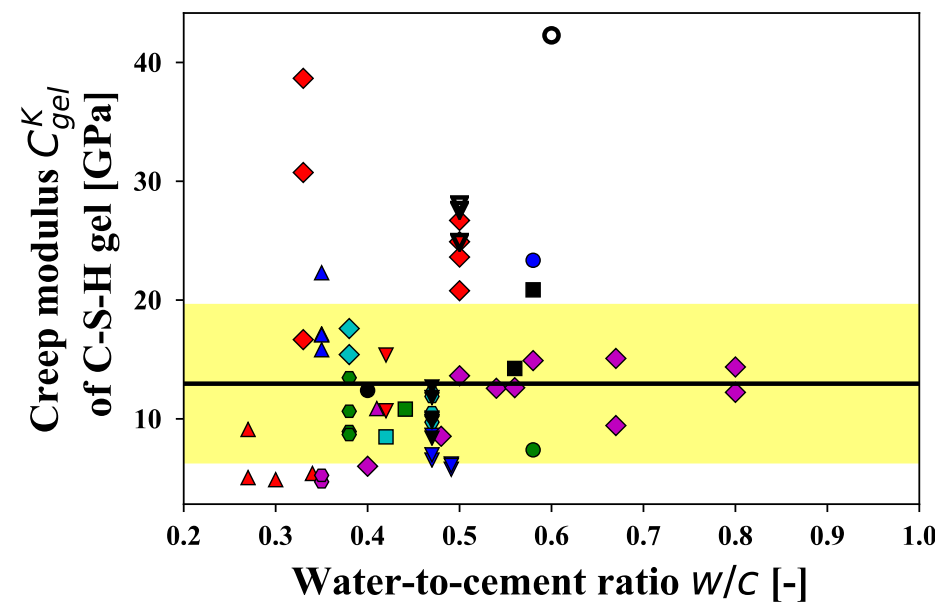

been shown to be a reliable tool to estimate the long-term creep kinetics of concrete [14], through a comparison of microindentation creep experiments with uniaxial basic creep experiments on concrete. In [14], Zhang et al. tested cement pastes that had the same mix design as those found in concrete samples manufactured and tested by Le Roy [10]. The excellent agreement that Zhang et al. obtained in [14] by comparing their data with Le Roy's data is consistent with the fact that, in Fig. 3, creep moduli of C-S-H back-calculated from Zhang's microindentation creep experiments almost overlap with those back-calculated from Le Roy's uniaxial creep experiments on concrete.

Figure 3: Bulk creep modulus of C-S-H gel as a function water-to-cement ratio, computed from basic creep data on concrete available in $[51,52,53$, $54,55,56,19,18,57,58,35,7,10,17,59,60]$ and from microindentation creep data on cement paste available in $[14,15]$. The mean value of $13 \mathrm{GPa}$ and standard deviation of $6.7 \mathrm{GPa}$ displayed in the figure are calculated by including the basic creep data on concrete only. 


\section{In-pore stress necessary to explain long-term kinetics of auto- genous shrinkage}

In this work we aim at testing the following hypothesis: may capillary forces due to self-desiccation be the driving force of the long-term kinetics of autogenous shrinkage? To do so, we compare the in-pore stress necessary to explain the long-term kinetics of autogenous shrinkage with the capillary stress induced by self-desiccation of concrete under autogenous conditions. In this section, we compute the in-pore mechanical stress $\sigma_{h}$ that should act on the mixture of C-S-H gel with capillary pores to explain the long-term kinetics characterized by the parameter $\alpha_{s h}$. The next section is devoted to compute the capillary stress due to self-desiccation.

We compute first the mechanical stress $\Sigma_{h}$ that should act on concrete to explain the long-term kinetics of autogenous shrinkage, which was captured through the fitted parameter $\alpha_{s h}$ (see Tab. 1), using Eq. 2. Then, we downscale the stress $\Sigma_{h}$ to the scale of the C-S-H gel to calculate the stress $\sigma$ that should act on the C-S-H gel to explain the long-term kinetics of autogenous shrinkage of the concrete. To do so, we perform two steps of downscaling. The two steps are the same as the first two steps of the downscaling scheme described in section 3.1 .

At each step, we are dealing with a composite made of a matrix that creeps with no asymptote and of spherical inclusions that do not creep. The matrix is subjected to a stress $\underline{\underline{\sigma}}$. We aim at computing an equivalent macroscopic stress $\underline{\underline{\Sigma}}$ that should act on the composite to obtain an identical strain 
response [39, 61, 41].

In the elastic case, the macroscopic stress reads [39, 61, 41]:

$$
\underline{\underline{\underline{\Sigma}}}=\left(1-f_{i}\right) \underline{\underline{\sigma}}:<\underline{\underline{\underline{\underline{A}}}}>_{m}
$$

where $f_{i}$ is the volume fraction of inclusions; $\underline{\underline{\underline{A}}}$ is the $4^{\text {th }}$-order strain localization tensor; $\langle g\rangle_{m}$ is the mean value of the parameter $g$ on the matrix domain. For an isotropic stress $\underline{\underline{\sigma}}=\sigma \underline{\underline{1}}$ where $\underline{\underline{1}}$ is the identity tensor (hence, $\underline{\underline{\Sigma}}=\Sigma \underline{\underline{1}})$, Eq. 14 can be simplified to a scalar form by taking the spherical part $A_{i}^{s p h}$ of the localization tensor $\underline{\underline{\underline{A}}}$ of the inclusion in the Mori-Tanaka's scheme [39]:

$$
\Sigma=\left(1-f_{i}\right) \sigma\left(\frac{1-f_{i} A_{i}^{s p h}}{1-f_{i}}\right)=\frac{\left(1+\frac{\alpha_{m}}{K_{m}}\left(K_{i}-K_{m}\right)\right)\left(1-f_{i}\right)}{1+\frac{\alpha_{m}}{K_{m}}\left(K_{i}-K_{m}\right)\left(1-f_{i}\right)} \sigma
$$

where $\alpha_{m}=3 K_{m} /\left(3 K_{m}+4 G_{m}\right)$. For $\nu_{m}=0.2$, we obtain $\alpha_{m}=1 / 2$.

In the viscoelastic case with the viscoelastic Poisson's ratio of the matrix $\nu_{m}(t)=0.2$, using the elastic-viscoelastic correspondence principle, we replace all elastic parameters in Eq. 15 by the $s$-multiplied Laplace transform of their corresponding viscoelastic operator. Then, considering that, at long term, the inclusion is much stiffer than the matrix, i.e., $K_{i}^{\infty} \gg K_{m}^{\infty}$, we use the final value theorem and obtain:

$$
\Sigma^{\infty}=\sigma^{\infty}
$$


In two steps of downscaling from the scale of concrete to the scale of the mixture of C-S-H gel with capillary pores, we use Eq. 16 twice. The in-pore stress $\Sigma_{h}$ that should act on concrete to explain the long-term kinetics of autogenous shrinkage corresponds to an identical stress $\sigma_{h}=\Sigma_{h}$ that should act on the mixture of $\mathrm{C}-\mathrm{S}-\mathrm{H}$ gel with capillary pores. Hence, combining Eqs. 2 and 12, we can relate this stress $\sigma_{h}$ to the fitted parameter $\alpha_{s h}$ via the bulk creep modulus $C_{g e l}^{K}$ of the C-S-H gel:

$$
\sigma_{h}=3 \alpha_{s h} C_{g e l}^{K}\left(\frac{1+f_{a}}{1-f_{a}}\right)\left(\frac{1+f_{b}}{1-f_{b}}\right)\left(\frac{1-\phi_{c}}{1+\phi_{c}}\right) .
$$

This equation provides the mechanical stress $\sigma_{h}$ that must act in the capillary pore system at the scale of the mixture of C-S-H gel with capillary pores to explain the long-term logarithmic kinetics of autogenous shrinkage of the concrete or cement paste specimen, characterized by the parameter $\alpha_{s h}$. For all autogenous shrinkage experiments considered in section 2.1, we compute the mechanical stress $\sigma_{h}$ from the measured parameter $\alpha_{s h}$ with Eq. 17 and display it as a function of water-to-cement ratio in Fig. 6. This stress $\sigma_{h}$ is going to be compared with the capillary forces due to self-desiccation in the next section.

\section{Capillary stress due to self-desiccation}

In this section, we first analyze experimental data of evolution of relative humidity under autogenous conditions to characterize the self-desiccation. Then, making use of Power's hydration model [46] and of the theory of 
poromechanics [62], we estimate the capillary stress due to self-desiccation. By comparing this capillary stress with the mechanical stress $\sigma_{h}$ calculated in the previous section, we check the hypothesis that capillary forces due to self-desiccation are the driving force of the long-term kinetics of autogenous shrinkage.

\subsection{Self-desiccation of cementitious materials}

Hydration of cement is a water-consuming process. In sealed conditions, i.e., in absence of any external water supply, consumption of water desaturates the cement paste as the porosity decreases less slowly than the quantity of water. As a result, the relative humidity inside the cement paste decreases [63]. Flatt et al. [64, 65] showed that hydration stops below a certain relative humidity. On the other hand, Jensen [63] showed that self-desiccation is limited by thermodynamics. Therefore, we expect that, under autogenous conditions, the relative humidity will reach an equilibrium value when hydration stops. The objective of this section is to relate this relative humidity at equilibrium to the water-to-cement ratio of the concrete or the cement paste.

Many authors $[66,67,68,69,70,71,72,73,74,75]$ measured relative humidity inside concrete or cement paste under autogenous conditions as a function of age. For each of these tests, author, year, water-to-cement ratio and duration of test are summarized in Tab. 3.

As the relative humidity is expected to reach an asymptotic value, we propose the following simple empirical relation for the evolution of relative 


\begin{tabular}{|l||l|l|l|l|}
\hline Author & $\mathrm{w} / \mathrm{c}^{1}[-]$ & $\tau_{T}{ }^{2}[$ days $]$ & $h_{r}^{\infty 3}[-]$ & $\tau_{h_{r}}{ }^{4}[$ days $]$ \\
\hline \hline Baroghel-Bouny (1991) & 0.35 & 800 & 0.87 & 237 \\
\hline Baroghel-Bouny (1991) & 0.49 & 365 & 0.94 & 52 \\
\hline Jensen (1996) & 0.30 & 1 & 0.89 & 0.12 \\
\hline Jensen (1996) & 0.35 & 14 & 0.93 & 0.71 \\
\hline Persson (1997) & 0.25 & 450 & 0.76 & 40 \\
\hline Persson (1997) & 0.33 & 450 & 0.82 & 62 \\
\hline Persson (1997) & 0.47 & 450 & 0.88 & 135 \\
\hline Persson (1997) & 0.58 & 450 & 0.94 & 98 \\
\hline Kim (1999) & 0.28 & 11 & 0.87 & 2.12 \\
\hline Kim (1999) & 0.40 & 11 & 0.91 & 2.24 \\
\hline Kim (1999) & 0.68 & 12 & 0.97 & 15.24 \\
\hline Yssorche (1999) & 0.33 & 365 & 0.84 & 15.24 \\
\hline Yssorche (1999) & 0.44 & 365 & 0.90 & 0.95 \\
\hline Yssorche (1999) & 0.59 & 365 & 0.99 & 0.57 \\
\hline Yssorche (1999) & 0.75 & 337 & 0.99 & 0.06 \\
\hline Jiang (2005) & 0.20 & 300 & 0.81 & 8.56 \\
\hline Jiang (2005) & 0.30 & 300 & 0.87 & 19.29 \\
\hline Jiang (2005) & 0.40 & 300 & 0.90 & 27.76 \\
\hline Jiang (2005) & 0.50 & 300 & 0.93 & 41.37 \\
\hline Zhutovsky (2013) & 0.21 & 7 & 0.81 & 0.44 \\
\hline Zhutovsky (2013) & 0.25 & 7 & 0.84 & 0.61 \\
\hline Zhutovsky (2013) & 0.33 & 7 & 0.86 & 0.62 \\
\hline Wyrzykowski (2016) & 0.21 & 7 & 0.78 & 4 \\
\hline Wyrzykowski (2016) & 0.24 & 7 & 0.79 & 5 \\
\hline Wyrzykowski (2016) & 0.30 & 7 & 0.83 & 5 \\
\hline Wyrzykowski (2016) & 0.35 & 7 & 0.88 & 4 \\
\hline Aili (2017) & 0.52 & 127 & 0.90 & 10 \\
\hline & & & & \\
\hline
\end{tabular}

Table 3: Summary of experimental data of evolution of relative humidity with respect to time under autogenous conditions, and of the fitted parameters. Data from $[66,67,68,69,70,71,72,73,74,75] .{ }^{1} \mathrm{w} / \mathrm{c}$ : water-to-cement ratio; ${ }^{2} \tau_{T}$ : duration of the test; ${ }^{3} h_{r}^{\infty}$ : long-term relative humidity under autogenous conditions, obtained by fitting of Eq. $18 ;{ }^{4} \tau_{h_{r}}$ : characteristic time of decrease of relative humidity under autogenous conditions, obtained by fitting of Eq. 18. 
humidity over time under autogenous conditions:

$$
h_{r}(t)=h_{r}^{\infty}+\left(1-h_{r}^{\infty}\right) \exp \left(-\frac{t}{\tau_{h_{r}}}\right)
$$

where $h_{r}^{\infty}$ and $\tau_{h_{r}}$ are fitted parameters which depend on the water-to-cement ratio and correspond to the long-term relative humidity and to a characteristic time, respectively. For the sake of simplicity, in Fig. 4 we present only the experimental measurements performed in [66] and the corresponding fit with Eq. 18. However, we analyzed a set of 27 experiments, see Fig. C.8 in Appendix C.

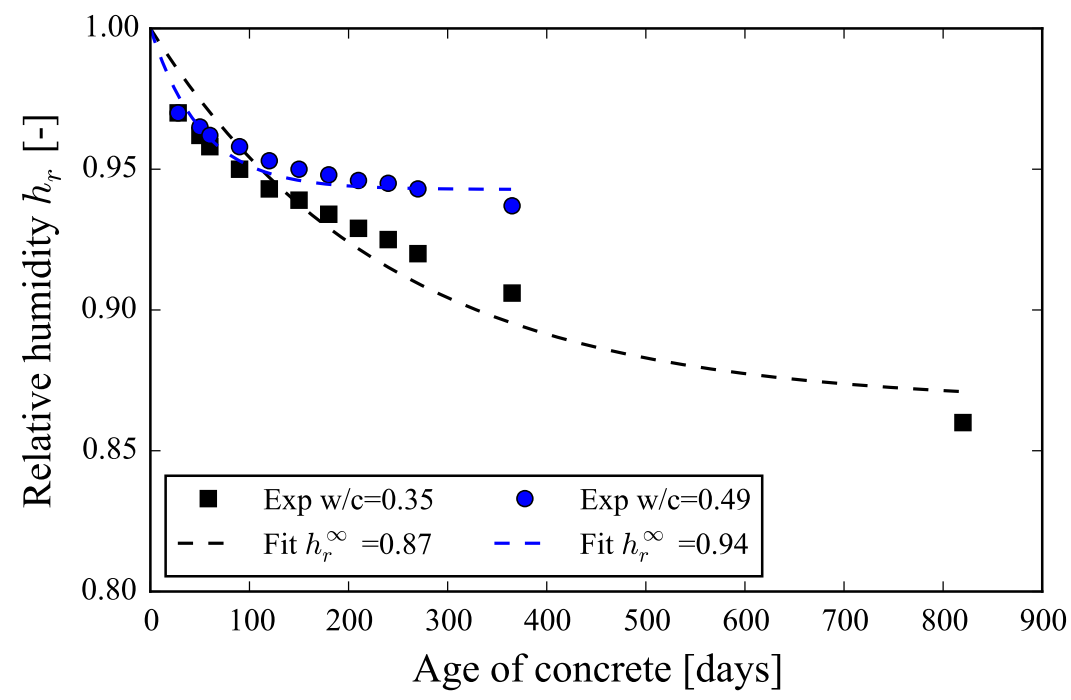

Figure 4: Evolution of relative humidity under autogenous conditions, data retrieved from [66].

To assess the importance of the choice of the fitting function in the estimation of long-term relative humidity, instead of Eq. 18, we also fit- 
ted the evolutions of relative humidity over time with a rational function $h_{r}(t)=\left(\left(h_{r}^{\infty}\right)^{2} t+\tau_{h_{r}}\right) /\left(h_{r}^{\infty} t+\tau_{h_{r}}\right)$ and with a hyperbolic function $h_{r}(t)=$ $\left.1-\left(1-h_{r}^{\infty}\right) \tanh \left(t / \tau_{h_{r}}\right)\right)$, where $h_{r}^{\infty}$ and $\tau_{h_{r}}$ are the fitting parameters. For the 27 tests considered, with respect to the fitting performed with Eq. 18, the fitted long-term relative humidity differed by a maximum of 0.039 when using the rational function, and by a maximum of 0.055 when using the hyperbolic function. Consequently, the fitted long-term relative humidity $h_{r}^{\infty}$ does not seem to depend much on the shape of the function used to fit the evolutions of relative humidity over time.

Since we are interested in the long-term kinetics of autogenous shrinkage, we listed the long-term relative humidities $h_{r}^{\infty}$ in Tab. 3 and plotted them against water-to-cement ratio in Fig. 5. From Fig. 5, we can see that the long-term relative humidity $h_{r}^{\infty}$ for a concrete with water-to-cement ratio $w / c$ will be comprised between values given by the following equations:

Upper bound for $h_{r}^{\infty}: h_{r, u}^{\infty}= \begin{cases}1-(0.4-w / c), & \text { if } w / c<0.4 \\ 1, & \text { otherwise }\end{cases}$

Lower bound for $h_{r}^{\infty}: h_{r, l}^{\infty}= \begin{cases}1-0.45(0.77-w / c), & \text { if } w / c<0.75 \\ 1, & \text { otherwise }\end{cases}$ 


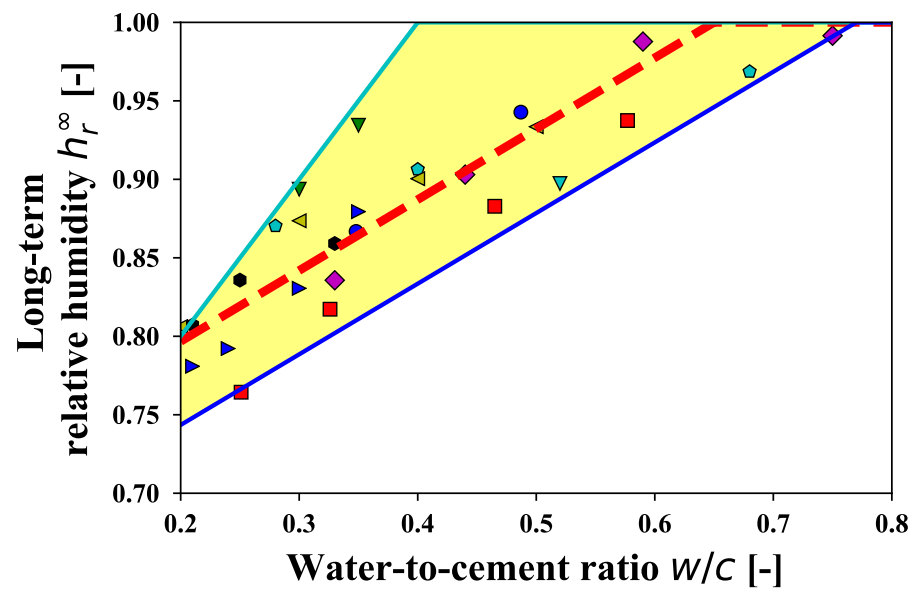

- Baroghel-Bouny (1991)

$\nabla$ Jensen (1996)

- Persson (1997)

- Kim (1999)

$\diamond \quad$ Yssorche (1999)

$\triangleleft \quad$ Jiang (2005)

- Zhutovsky (2013)

- Wyrzykowski (2016)

$\nabla \quad$ Aili (2017)

- Best fit $h_{r}^{\infty}$

Upper bound $h_{r, u}^{\infty}$

Lower bound $h_{r, l}^{\infty}$

Figure 5: Long-term relative humidity under autogenous conditions as a function water-to-cement ratio, computed from experimental data in $[66,67$, 68, 69, 70, 71, 72, 73, 74, 75].

\subsection{Estimation of capillary force}

Partially saturated poromechanics, under the assumption of pore isodeformation, states that the capillary stress due to capillary pressure is equal to $b S_{l} P_{c}$, where $P_{c}$ is the capillary pressure, $S_{l}$ is the saturation degree in liquid water and $b$ is the Biot coefficient (see Eq. 9.77 in [62]). In the following, we compute those three parameters.

The long-term relative humidity $h_{r}^{\infty}$ in autogenous conditions, displayed in Fig. 5, can be expressed as [76]:

$$
h_{r}^{\infty}=h_{r, K}^{\infty} h_{r, S}^{\infty}
$$

where $h_{r, K}^{\infty}$ captures the variations of relative humidity solely due to surface tension effects and to the curvature of the fluid/vapour menisci in the pore 
space, and where $h_{r, S}^{\infty}$ captures the variations of relative humidity due to the presence of ions in the pore solution. The term $h_{r, S}^{\infty}$ can be estimated with Raoult's law [62] to be equal to the long-term molar fraction of water in the pore solution. The term $h_{r, K}^{\infty}$ can be related to capillary pressure through a combination of Kelvin's equation with Laplace equation:

$$
P_{c}=-\frac{R T}{V_{w}} \log \left(h_{r, K}^{\infty}\right),
$$

where $R, T$ and $V_{w}$ are the ideal gas constant, the absolute temperature and the molar volume of water, respectively.

Combining Eqs. 21 and 22 makes it possible to compute the capillary pressure $P_{c}$ from the long-term relative humidity $h_{r}^{\infty}$ and the molar fraction of water in the pore solution. However, the composition of the pore solution has not been much measured for cement pastes under autogenous condition in the long term, despite numerous studies [67, 77, 21, 78, 25, 79, 80] devoted to the effect of ions in the pore solution of cement pastes. Chen et al. [79] measured the concentration of ions in a cement paste with water-to-cement mass ratio of 0.4 at the age of 7 days, for which, based on their measured ion concentration of $1.6 \mathrm{~mol} / \mathrm{L}$, we calculate a molar fraction of water around 0.97. $\mathrm{Hu}[80]$ measured the concentration of ions for cement pastes with water-to-cement mass ratios of $0.3,0.35,0.39$ and 0.46 , up to the age of 28 days, and showed that $h_{r, S}$ is around $97 \%$. In absence of any long-term measurement, we hence assumed that, for all cement pastes considered in 
this study, the long-term parameter $h_{r, S}^{\infty}$ was equal to 0.97. A combined use of Eq. 21 and Eq. 22 then makes it possible to estimate the capillary pressure $P_{c}$ from the long-term relative humidity. Considering the upper bound $h_{r, u}^{\infty}$ of long-term relative humidity leads a lower bound $P_{c, l}$ of the capillary pressure, while considering the lower bound $h_{r, l}^{\infty}$ of long-term relative humidity leads an upper bound $P_{c, u}$ of the capillary pressure.

The saturation degree $S_{l}$ (i.e., the volume fraction of the capillary and gel pores spaces that is occupied with liquid water with respect to the total volume of capillary and gel pores) is computed, in the same manner as in [21], from Power's model as follows: For a given volume $V$ of cement paste, the volume $V_{p}$ of total pore space is equal to the total volume minus the volume $0.53(1-p) \xi^{\infty} V$ of portlandite, $0.32(1-p) \xi^{\infty} V$ of AFt and AFm phases, $(1-p)\left(1-\xi^{\infty}\right) V$ of clinker and $V_{\mathrm{CSH}}=1.52(1-p)\left(1-\alpha^{\infty}\right) V$ of C-S-H solid (i.e., C-S-H without its gel porosity). The volume of chemical shrinkage is equal to $V_{c s}=0.20(1-p) \xi^{\infty} V$. The saturation degree $S_{l}$ is then obtained as:

$$
S_{l}=1-\frac{V_{c s}}{V_{p}}=\frac{p-0.72(1-p) \alpha^{\infty}}{p-0.52(1-p) \alpha^{\infty}} .
$$

The Biot coefficient is computed by two steps of upscaling:

- In the first step, at the scale of the C-S-H gel, we compute the porosity of the C-S-H gel as the mean value of the porosity of high-density CS-H and low-density C-S-H: considering that $40 \%$ of C-S-H gel is high- 
density C-S-H with porosity 0.24 , and the other $60 \%$ is low-density C-S-H with porosity 0.37 [81], the mean porosity of C-S-H gel is estimated to be equal to $\phi_{\text {gel }}=0.32$. Considering that the $\mathrm{C}-\mathrm{S}-\mathrm{H}$ gel is composed from spherical C-S-H particles and gel pores, we apply the self-consistent homogenization scheme. From micro-poroelasticity, the tensor of Biot coefficients for a porous material reads [82]:

$$
\underline{\underline{b^{h o m}}}=\phi_{0} \underline{\underline{1}}:<\underline{\underline{\underline{\underline{A}}}}>_{p}=\underline{\underline{1}}:\left(\underline{\underline{I}}-f_{s}<\underline{\underline{\underline{\underline{A}}}}>_{s}\right)
$$

where subscripts $p$ and $s$ indicate the pore space and the solid skeleton, respectively, while $\phi_{0}$ is the initial porosity. For the $\mathrm{C}-\mathrm{S}-\mathrm{H}$ gel, for which the Poisson's ratio is assumed equal to 0.2 (see section 3.1), we introduce the strain localization tensor of the self-consistent scheme in Eq. 24, which leads the Biot coefficient $b_{g e l}$ of the C-S-H gel:

$$
b_{g e l}=2 \phi_{g e l} .
$$

In the viscoelastic case, using the elastic-viscoelastic correspondence principle, we replace the elastic parameters in Eq. 25 with the $s$ multiplied Laplace transform of their corresponding viscoelastic operator. At long term, we consider that the microstructure of the material does not evolve anymore, from which follows that the gel porosity $\phi_{\text {gel }}$ is constant over time. As a result, Eq. 25 holds true for the viscoelastic 
case, under the hypothesis that the viscoelastic Poisson's ratio of the C-S-H gel is constant and equal to 0.2 .

- In the second step, at the scale of the mixture of C-S-H gel with capillary pores (Fig. 2c), we consider the Biot coefficient of a composite made from a porous matrix (i.e., C-S-H gel) and capillary pores. As was done by Pichler et al. [41] or by Ghabezloo [82], we assume that the pores at the various scales are connected and that the pore pressure is identical in all pores. For such porous materials with pores at various scales, micro-poroelasticity provides the following tensor of Biot coefficients [82]:

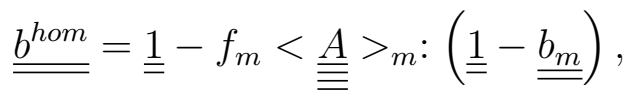

where the subscript $m$ indicates the solid skeleton, which here acts as a matrix. For the mixture of the C-S-H gel with capillary pores, in the elastic case, assuming again the Poisson's ratio of the C-S-H gel equal to 0.2 (see section 3.1), we apply the Mori-Tanaka's homogenization scheme by introducing the Mori-Tanaka strain localization tensor into Eq. 26, from which we obtain the Biot coefficient $b$ of the mixture of C-S-H gel with capillary pores:

$$
b=1-\frac{1-\phi_{c}}{1+\phi_{c}}\left(1-b_{g e l}\right) .
$$


In the viscoelastic case, using the elastic-viscoelastic correspondence principle, we replace the elastic parameters in Eq. 27 with the $s$ multiplied Laplace transform of their corresponding viscoelastic operator. At long term, we consider again that the microstructure of the material does not evolve anymore, from which follows that Eq. 27 holds true for the viscoelastic case (again, under the hypothesis that the viscoelastic Poisson's ratio of the C-S-H gel is constant and equal to 0.2 ).

Knowing the upper bound $P_{c, u}$ and lower bound $P_{c, l}$ of capillary pressure, the saturation degree $S_{l}$, and the Biot coefficient $b$ of the sample, we estimate the upper bound $b S_{l} P_{c, u}$ and lower bound $b S_{l} P_{c, l}$ of the macroscopic mechanical volumetric compressive stress due to the capillary forces acting on the mixture of capillary pores with C-S-H gel. The upper and lower bounds of the stress $b S_{l} P_{c}$ are displayed in Fig. 6, from which we can observe that the stress $b S_{l} P_{c}$ increases with a decreasing water-to-cement ratio and reaches about 15 to $20 \mathrm{MPa}$ for a water-to-cement ratio equal to 0.2 .

It is worth mentioning that the two-step procedure here used to upscale the Biot coefficient assumes that both capillary pores and gel pores are subjected to the same capillary stress $b S_{l} P_{c}$, which is not verified in practice. Indeed, water starts to evaporate from gel pores only when the relative humidity drops below $40 \%$ [81] while, under autogenous condition, the relative humidity remains always above $75 \%$, as shown in Fig. 5. Therefore, in longterm autogenous conditions, the gel pores remain fully saturated. In contrast, 


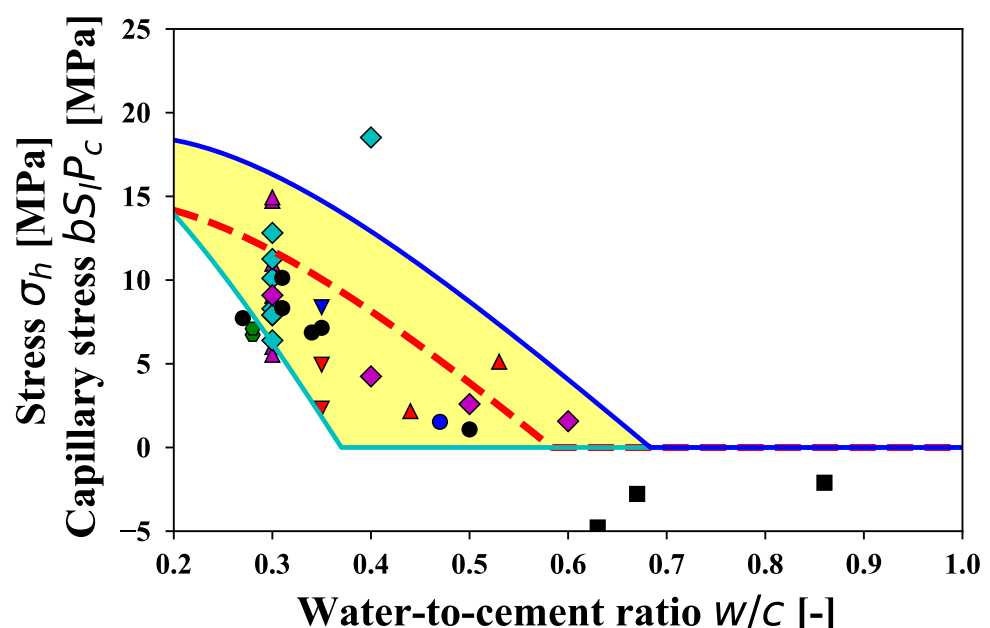

Figure 6: Mechanical stress $\sigma_{h}$ that should act on the mixture of C-S-H gel displayed together with capillary pores to explain the long-term kinetics of autogenous shrinkage of data in $[19,35,7,87,88,89,90,91,92,17,93,94]$, displayed together with estimated bounds of the capillary stress $b S_{l} P_{c}$. 
illary forces and acting on the mixture of C-S-H gel and capillary pores with the mechanical stress $\sigma_{h}$ that should act to explain the long-term kinetics of autogenous shrinkage characterized by the parameter $\alpha_{s h}$ fitted on the measurements. The capillary stress obtained from the best fit on the long-term relative humidity slightly overestimates the experimentally backcalculated mechanical stress $\sigma_{h}$, even though those two quantities exhibit quite similar trends with water-to-cement ratio. However, almost all points of the mechanical stress $\sigma_{h}$ back-calculated from experiments lie between the model-predicted upper bound and lower bound of the stress $b S_{l} P_{c}$ induced by capillary forces. Therefore, we conclude that the long-term kinetics of autogenous shrinkage is compatible with the hypothesis that the evolution of autogenous shrinkage in the long term is due to creep under the action of capillary forces due to self-desiccation.

\section{Discussion on the choice of hydration model}

Powers' hydration model [46] was used to quantify the volume fractions of the different phases in the multiscale microstructure of cement paste displayed in Fig. 2. Based on water vapor sorption isotherms, this model provides the amount of capillary water and physically adsorbed water. Powers' model considers the porosity of hydrates to be rather constant, which is why we considered a constant gel porosity $\phi_{g e l}$ while estimating the Biot coefficient of the C-S-H gel (see section 5.2).

Recently, nuclear magnetic resonance (NMR) measurements of Muller et 
al. $[95,96]$ showed that the density of the C-S-H gel varies: the gel porosity depends on water-to-cement ratio and hydration degree. Königsberger et al. [97] proposed an alternative hydration model that takes into account this densification effect explicitly. In this section, we check how different the capillary stresses $b S_{l} P_{c}$ estimated with this alternative hydration model are from the ones computed with Powers's model in section 5.2 and displayed in Fig. 6.

In a first step, based on the hydration model of Königsberger et al.[97], we compute the alternative volume fractions $f_{b}$ of portlandite, AFt and AFm phases and unhydrated clinker and $\phi_{c}$ of capillary pores, which intervene in Eq. 13. Using these alternative volume fractions $f_{b}$ and $\phi_{c}$, we perform again the analysis of basic creep data, following the same procedure as in section 3.3, from which we obtain a mean bulk creep modulus of C-S-H gel of $10 \mathrm{GPa}$ with a standard deviation of $6.3 \mathrm{GPa}$. Then, using again those alternative volume fractions $f_{b}$ and $\phi_{c}$, we perform the analysis of autogenous shrinkage data following the same procedure as in section 4 and calculate the mechanical stress $\sigma_{h}$ that should act on the mixture of C-S-H gel with capillary pores to explain the long-term kinetics of autogenous shrinkage as a creep phenomenon. This stress $\sigma_{h}$ is displayed in Fig. 7. For the sake of consistency, we used the same limits for the axes of this figure as for those of Fig. 6: note that, for Tazawa's sample at a water-to-cement mass ratio of 0.4 , the calculation yields $\sigma_{h}=30.2 \mathrm{MPa}$, which is outside of the figure.

In a second step, we compute the Biot coefficient and saturation degree 


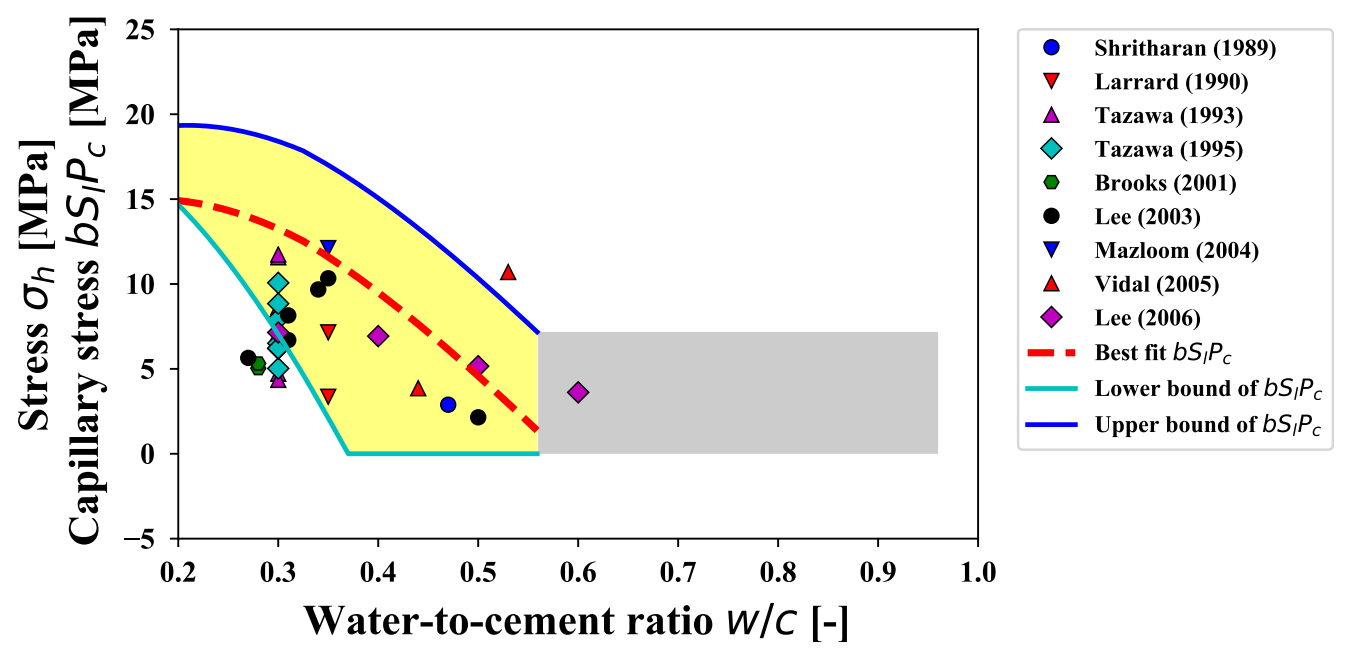

Figure 7: Mechanical stress $\sigma_{h}$ that should act on the mixture of C-S-H gel with capillary pores to explain the long-term kinetics of autogenous shrinkage as a creep phenomenon (data from $[19,35,7,87,88,89,90,91,92,17,93,94]$ ), displayed together with estimated bounds of the capillary stress $b S_{l} P_{c}$. All volume fractions in the multiscale scheme of concrete are computed based on the hydration model of Königsberger et al [97].

based on the alternative volume fractions $\phi_{c}$ of capillary pores and $\phi_{g e l}$ of gel pores obtained from the hydration model of Königsberger et al. The gel porosity $\phi_{g e l}$ is then a function of the water-to-cement mass ratio. In Königsberger's hydration model, the gel porosity $\phi_{g e l}$ is higher than 0.5 for cement pastes with water-to-cement mass ratio higher than 0.55 if the hydration degree is taken to be equal to $\xi^{\infty}=1-\exp (-3.3 w / c)$ [48]. The applicability of the self-consistent scheme with spherical particles that we used for homogenizing the $\mathrm{C}-\mathrm{S}-\mathrm{H}$ gel is limited to cases where the volume fraction of pores is lower than 0.5. Hence, we limited our analysis to waterto-cement mass ratios lower than 0.55 for the estimation of the capillary 
stress $b S_{l} P_{c}$. The alternative values of Biot coefficient and saturation provide alternative boundaries of the capillary stress $b S_{l} P_{c}$, which are displayed in Fig. 7 against the mechanical stress $\sigma_{h}$. We observe that Fig. 7 does not differ much from Fig. 6. Therefore, using Königsberger's model than Powers' model to calculated volume fraction still allows us to conclude that the long-term kinetics of autogenous shrinkage is compatible with the hypothesis that the evolution of autogenous shrinkage in the long term is due to creep under the action of capillary forces due to self-desiccation.

\section{Conclusions}

We performed an exhaustive study of experimental data from the literature on basic creep and autogenous shrinkage. We downscaled these results with the help of elastic homogenization schemes extended to linear viscoelasticity and discussed the origin of long-term autogenous shrinkage using the theory of poromechanics. Several conclusions can be drawn:

- For materials that are kept under autogenous conditions, the creep modulus of C-S-H gel exhibits no specific trend with water-to-cement ratio, with a mean value of $13 \pm 6.7 \mathrm{GPa}$. This creep modulus is lower than the value obtained from microindentation testing [14, 15], which is $32 \mathrm{GPa}$.

- For concretes made with a water-to-cement mass ratio below 0.5, the autogenous shrinkage is not asymptotic and evolves logarithmically 
with respect to time in the long term. In contrast, for concretes with a water-to-cement mass ratio larger than 0.5 , under the hypothesis that autogenous shrinkage is due to creep under the action of capillary forces due to self-desiccation, autogenous shrinkage is negligible.

- An upper bound and a lower bound are proposed for the long-term relative humidity under autogenous conditions by analyzing experimental measurements of internal relative humidity over time from the literature.

- The long-term stress $b S_{l} P_{c}$ induced by the capillary forces due to selfdesiccation (see Fig. 6) increases with a decreasing water-to-cement ratio and reaches about 15 to $20 \mathrm{MPa}$ for a water-to-cement ratio equal to 0.2 .

- The long-term kinetics of the logarithmically-evolving autogenous shrinkage is compatible with the hypothesis that, in the long term, the increase of autogenous shrinkage is due to creep under the action of capillary forces due to self-desiccation.

\section{Acknowledgments}

The authors acknowledge financial support from EDF and thank EDF for this support.

The authors thank Dr. Siavash Ghabezloo for his help in estimating the Biot coefficient. 


\section{Appendix A. Autogenous shrinkage database}

This section is devoted to present autogenous shrinkage data that are displayed in Fig. 6. For each data are given author and year of the work, file number that corresponds database [34] collected in Northwestern University, mix design properties and long-term log-slope of autogenous shrinkage, see Tab. A.4 and A.5.

\section{Appendix B. Basic creep database}

This section is devoted to present basic creep data that are displayed in Fig. 3. For each data are given author and year of the work, file number that corresponds database [34] collected in Northwestern University, mix design properties, age of loading and long-term log-slope of basic creep, see Tabs. B.6 and B.7.

\section{Appendix C. Experimental data of evolution of relative humidity with respect to time under autogenous conditions}

This section is devoted to present the experimental data of evolution of relative humidity under autogenous conditions. For each data, the fitted long-term relative humidity $h_{r}^{\infty}$ is displayed in legend of figure, see Fig. C.8 


\begin{tabular}{|l||l|l|l|l|l|}
\hline Author & File & $\mathrm{w} / \mathrm{c}^{2}$ & $\mathrm{a} / \mathrm{c}^{3}$ & $\mathrm{c}^{4}$ & $\alpha_{s h}{ }^{6}$ \\
\hline \hline Brooks (1984) & e_074_20 & 0.67 & 4.75 & 366 & -26.3 \\
\hline Brooks (1984) & e_074_29 & 0.76 & 4.75 & 383 & -98.94 \\
\hline Brooks (1984) & e_074_30 & 0.62 & 4.75 & 344 & -83.22 \\
\hline Brooks (1984) & e_074_33 & 0.86 & 4.75 & 457 & -46.73 \\
\hline Brooks (1984) & e_074_35 & 0.63 & 4.75 & 387 & -42.43 \\
\hline Shritharan (1989) & e_079_6 & 0.47 & 5.09 & 393 & 7.51 \\
\hline Larrard (1990) & A_022_2 & 0.35 & 3.96 & 450 & 82.13 \\
\hline Larrard (1990) & A_022_3 & 0.35 & 3.96 & 450 & 7.49 \\
\hline Larrard (1990) & A_022_5 & 0.35 & 3.96 & 450 & 15.96 \\
\hline Tazawa (1993) & A_062_6 & 0.3 & 0 & 533 & 129.92 \\
\hline Tazawa (1993) & A_062_7 & 0.3 & 0 & 533 & 221.16 \\
\hline Tazawa (1993) & A_062_8 & 0.3 & 0 & 533 & 224.33 \\
\hline Tazawa (1993) & A_062_9 & 0.3 & 0 & 533 & 90.08 \\
\hline Tazawa (1993) & A_062_12 & 0.3 & 0 & 533 & 83.14 \\
\hline Tazawa (1993) & A_062_13 & 0.3 & 0 & 533 & 136.05 \\
\hline Tazawa (1993) & A_062_14 & 0.3 & 0 & 533 & 132.06 \\
\hline Tazawa (1993) & A_062_15 & 0.3 & 0 & 533 & 164.82 \\
\hline Tazawa (1995) & A_063_22 & 0.3 & 0 & NAN & 1.71 \\
\hline Tazawa (1995) & A_063_27 & 0.4 & 0 & NAN & 1.69 \\
\hline Tazawa (1995) & A_063_39 & 0.3 & 0 & NAN & 4.35 \\
\hline Tazawa (1995) & A_063_42 & 0.3 & 0 & NAN & 2.42 \\
\hline Tazawa (1995) & A_063_44 & 0.3 & 0 & NAN & 0.03 \\
\hline Tazawa (1995) & A_063_49 & 0.3 & 0 & NAN & 9.01 \\
\hline Tazawa (1995) & A_063_50 & 0.3 & 0 & NAN & 8.49 \\
\hline Tazawa (1995) & A_063_51 & 0.3 & 0 & NAN & 8.85 \\
\hline
\end{tabular}

Table A.4: Details of autogenous shrinkage data (first part). ${ }^{1}$ File corresponds to the file number in the database compiled by Prof. Bažant and his collaborators [34]; ${ }^{2} \mathrm{w} / \mathrm{c}$ : water-to-cement ratio; ${ }^{3} \mathrm{a} / \mathrm{c}$ : aggregate-to-cement mass ratio; ${ }^{4} \mathrm{c}$ : cement per volume of mixture $\left[\mathrm{kg} / \mathrm{m}^{3}\right] ;{ }^{5} \alpha_{s h}$ : Fitted parameter in Eq. $1[\mu \mathrm{m} / \mathrm{m}]$. 


\begin{tabular}{|l||l|l|l|l|l|}
\hline Author & File $^{1}$ & $\mathrm{w} / \mathrm{c}^{2}$ & $\mathrm{a} / \mathrm{c}^{3}$ & $\mathrm{c}^{4}$ & $\alpha_{s h}{ }^{6}$ \\
\hline \hline Weiss (1998) & A_068_1 & 0.3 & 3.04 & 485 & 63.01 \\
\hline Weiss (1998) & A_068_16 & 0.3 & 3.04 & 485 & 59.57 \\
\hline Weiss (1998) & A_068_19 & 0.3 & 3.04 & 485 & 61.54 \\
\hline Brooks (2001) & A_007_8 & 0.28 & 4 & 450 & 14.39 \\
\hline Brooks (2001) & A_007_12 & 0.28 & 4 & 450 & 15.18 \\
\hline Lee (2003) & A_023_1 & 0.5 & 4.66 & 370 & 5.59 \\
\hline Lee (2003) & A_023_2 & 0.35 & 3.85 & 450 & 23.07 \\
\hline Lee (2003) & A_023_3 & 0.31 & 3.4 & 500 & 24.23 \\
\hline Lee (2003) & A_023_4 & 0.27 & 3.05 & 550 & 19.58 \\
\hline Lee (2003) & A_023_8 & 0.34 & 3.73 & 440 & 20.44 \\
\hline Lee (2003) & A_023_9 & 0.31 & 3.4 & 500 & 29.5 \\
\hline Zhang (2003) & A_072_1 & 0.26 & 3.7 & 496 & 38.97 \\
\hline Zhang (2003) & A_072_2 & 0.3 & 3.6 & 497 & 40.17 \\
\hline Mazloom (2004) & A_031_2 & 0.35 & 3.7 & 500 & 30.64 \\
\hline Vidal (2005) & A_065_3 & 0.44 & 3.7 & 450 & 10.95 \\
\hline Vidal (2005) & A_065_5 & 0.53 & 5.25 & 350 & 27.99 \\
\hline Lee (2006) & A_024_1 & 0.3 & 2.73 & 583 & 29.96 \\
\hline Lee (2006) & A_024_2 & 0.4 & 3.92 & 438 & 17.17 \\
\hline Lee (2006) & A_024_3 & 0.5 & 5.09 & 350 & 12.57 \\
\hline Lee (2006) & A_024_4 & 0.6 & 6.43 & 292 & 9 \\
\hline
\end{tabular}

Table A.5: Details of autogenous shrinkage data (second part). ${ }^{1}$ File corresponds to the file number in the database compiled by Prof. Bažant and his collaborators [34]; ${ }^{2} \mathrm{w} / \mathrm{c}$ : water-to-cement ratio; ${ }^{3} \mathrm{a} / \mathrm{c}$ : aggregate-to-cement mass ratio; ${ }^{4} \mathrm{c}$ : cement per volume of mixture $\left[\mathrm{kg} / \mathrm{m}^{3}\right] ;{ }^{5} \alpha_{s h}$ : Fitted parameter in Eq. $1[\mu \mathrm{m} / \mathrm{m}]$. 


\begin{tabular}{|l||l|l|l|l|l|l|}
\hline Author & File ${ }^{1}$ & $\mathrm{w} / \mathrm{c}^{2}$ & $\mathrm{a} / \mathrm{c}^{3}$ & $\mathrm{c}^{4}$ & $\mathrm{t}_{0}{ }^{5}$ & $1 / C_{c}^{E 6}$ \\
\hline \hline Hanson (1953a) & C_002_1 & 0.58 & 5.62 & 346 & 28 & 6.76 \\
\hline Hanson (1953a) & C_002_3 & 0.56 & 6.14 & 320 & 7 & 8.39 \\
\hline Hanson (1953b) & C_101_1 & 0.58 & 9.6 & 362 & 28 & 6.37 \\
\hline Browne (1967) & C_025_15 & 0.42 & 4.4 & 418 & 28 & 5.94 \\
\hline Browne (1967) & C_025_16 & 0.42 & 4.4 & 418 & 60 & 8.54 \\
\hline Rostasy (1972) & C_043_3 & 0.41 & 5.59 & 332 & 28 & 6.13 \\
\hline Kommendant (1976a) & C_104_1 & 0.38 & 4.34 & 419 & 28 & 4.88 \\
\hline Kommendant (1976a) & C_104_2 & 0.38 & 4.34 & 419 & 90 & 4.28 \\
\hline Kommendant (1976b) & C_054_1 & 0.38 & 4.34 & 419 & 28 & 8.42 \\
\hline Kommendant (1976b) & C_054_2 & 0.38 & 4.34 & 419 & 90 & 8.67 \\
\hline Kommendant (1976b) & C_054_14 & 0.38 & 4.03 & 449 & 28 & 6.07 \\
\hline Kommendant (1976b) & C_054_15 & 0.38 & 4.03 & 449 & 90 & 7.67 \\
\hline Takahashi (1980) & J_015_3 & 0.4 & 4.45 & 400 & 30 & 6.35 \\
\hline Kawasumi (1982) & J_018_1 & 0.47 & 6.01 & 304 & 7 & 9.16 \\
\hline Kawasumi (1982) & J_018_2 & 0.47 & 6.01 & 304 & 28 & 12.08 \\
\hline Kawasumi (1982) & J_018_3 & 0.47 & 6.01 & 304 & 91 & 11.32 \\
\hline Kawasumi (1982) & J_018_9 & 0.49 & 6.79 & 286 & 7 & 12.96 \\
\hline Kawasumi (1982) & J_018_10 & 0.49 & 6.79 & 286 & 28 & 13.95 \\
\hline Kawasumi (1982) & J_018_11 & 0.49 & 6.79 & 286 & 91 & 13.21 \\
\hline Brooks (1983) & C_072_2 & 0.27 & 3.3 & 535 & 28 & 5.83 \\
\hline Brooks (1983) & C_072_3 & 0.34 & 2.6 & 608 & 28 & 17.62 \\
\hline Brooks (1983) & C_072_4 & 0.27 & 2.6 & 628 & 28 & 12.75 \\
\hline Brooks (1983) & C_072_5 & 0.3 & 2.08 & 725 & 28 & 19.21 \\
\hline Brooks (1984) & C_074_19 & 0.8 & 4.75 & 405 & 14 & 24.09 \\
\hline Brooks (1984) & C_074_20 & 0.67 & 4.75 & 366 & 14 & 13.61 \\
\hline Brooks (1984) & C_074_21 & 0.58 & 4.75 & 337 & 14 & 9.17 \\
\hline Brooks (1984) & C_074_22 & 0.54 & 4.75 & 326 & 14 & 9.01 \\
\hline Brooks (1984) & C_074_23 & 0.5 & 4.75 & 311 & 14 & 6.73 \\
\hline Brooks (1984) & C_074_24 & 0.8 & 4.75 & 389 & 14 & 26.88 \\
\hline Brooks (1984) & C_074_25 & 0.67 & 4.75 & 351 & 14 & 20.68 \\
\hline Brooks (1984) & C_074_26 & 0.56 & 4.75 & 317 & 14 & 9.36 \\
\hline
\end{tabular}

Table B.6: Details of basic creep data (first part). ${ }^{1}$ File corresponds to the file number in the database compiled by Prof. Bažant and his collaborators [34]; ${ }^{2} \mathrm{w} / \mathrm{c}$ : water-to-cement ratio; ${ }^{3} \mathrm{a} / \mathrm{c}$ : aggregate-to-cement mass ratio; ${ }^{4} \mathrm{c}$ : cement per volume of mixture $\left[\mathrm{kg} / \mathrm{m}^{3}\right] ;{ }^{5} \mathrm{t}_{0}$ : loading age [days]; ${ }^{6} 1 / C_{c}^{E}$ : Fitted parameter in Eq. $3[\mu \mathrm{m} / \mathrm{m} / \mathrm{MPa}]$. 


\begin{tabular}{|l||l|l|l|l|l|l|}
\hline Author & Fill $^{1}$ & $\mathrm{w} / \mathrm{c}^{2}$ & $\mathrm{a} / \mathrm{c}^{3}$ & $\mathrm{c}^{4}$ & $\mathrm{t}_{0}{ }^{5}$ & $1 / C_{c}^{E 6}$ \\
\hline \hline Brooks (1984) & C_074_27 & 0.48 & 4.75 & 292 & 14 & 9.21 \\
\hline Brooks (1984) & C_074_28 & 0.4 & 4.75 & 267 & 14 & 8.29 \\
\hline Bryant (1987) & D_075_1 & 0.47 & 1.37 & 390 & 8 & 8.63 \\
\hline Bryant (1987) & D_075_2 & 0.47 & 1.37 & 390 & 14 & 8.86 \\
\hline Bryant (1987) & D_075_3 & 0.47 & 1.37 & 390 & 21 & 10.83 \\
\hline Bryant (1987) & D_075_4 & 0.47 & 1.37 & 390 & 28 & 10.28 \\
\hline Bryant (1987) & D_075_5 & 0.47 & 1.37 & 390 & 84 & 10.01 \\
\hline Larrard (1988) & C_122_4 & 0.44 & 3.75 & 410 & 28 & 9.08 \\
\hline Shritharan (1989) & C_079_7 & 0.47 & 5.09 & 390 & 8 & 8.3 \\
\hline Shritharan (1989) & C_079_8 & 0.47 & 5.09 & 390 & 14 & 8.93 \\
\hline Shritharan (1989) & C_079_9 & 0.47 & 5.09 & 390 & 21 & 12.57 \\
\hline Shritharan (1989) & C_079_10 & 0.47 & 5.09 & 390 & 28 & 10.47 \\
\hline Shritharan (1989) & C_079_11 & 0.47 & 5.09 & 390 & 84 & 10.78 \\
\hline Larrard (1990) & D_022_2 & 0.35 & 3.96 & 450 & 5 & 4.42 \\
\hline Larrard (1990) & D_022_3 & 0.35 & 3.96 & 450 & 3 & 3.14 \\
\hline Larrard (1990) & D_022_4 & 0.35 & 3.96 & 450 & 7 & 4.08 \\
\hline Larrard (1990) & D_022_5 & 0.35 & 3.96 & 450 & 3 & 4.1 \\
\hline Leroy (1995) & C_123_1 & 0.5 & 5.46 & 342 & 0.83 & 4.11 \\
\hline Leroy (1995) & C_123_3 & 0.5 & 5.46 & 342 & 3 & 3.83 \\
\hline Leroy (1995) & C_123_4 & 0.5 & 5.46 & 342 & 7 & 4.33 \\
\hline Leroy (1995) & C_123_5 & 0.5 & 5.46 & 342 & 28 & 4.92 \\
\hline Leroy (1995) & C_123_34 & 0.33 & 4.35 & 426 & 3 & 1.52 \\
\hline Leroy (1995) & C_123_35 & 0.33 & 4.35 & 426 & 7 & 1.91 \\
\hline Leroy (1995) & C_123_36 & 0.33 & 4.35 & 426 & 28 & 3.52 \\
\hline Mazloom (2004) & D_031_2 & 0.35 & 3.7 & 500 & 7 & 16.86 \\
\hline Mazloom (2004) & D_031_10 & 0.35 & 3.7 & 500 & 28 & 15.1 \\
\hline Mazzotti (2005) & D_033_3 & 0.42 & 4.32 & 418 & 7 & 10.75 \\
\hline Mu (2009) & D_036_11 & 0.58 & 7.15 & 275 & 3 & 14.61 \\
\hline
\end{tabular}

Table B.7: Details of basic creep data (second part). ${ }^{1}$ File corresponds to the file number in the database compiled by Prof. Bažant and his collaborators [34]; ${ }^{2} \mathrm{w} / \mathrm{c}$ : water-to-cement ratio; ${ }^{3} \mathrm{a} / \mathrm{c}$ : aggregate-to-cement mass ratio; ${ }^{4} \mathrm{c}$ : cement per volume of mixture $\left[\mathrm{kg} / \mathrm{m}^{3}\right] ;{ }^{5} \mathrm{t}_{0}$ : loading age [days]; ${ }^{6} 1 / C_{c}^{E}$ : Fitted parameter in Eq $3[\mu \mathrm{m} / \mathrm{m} / \mathrm{MPa}]$. 


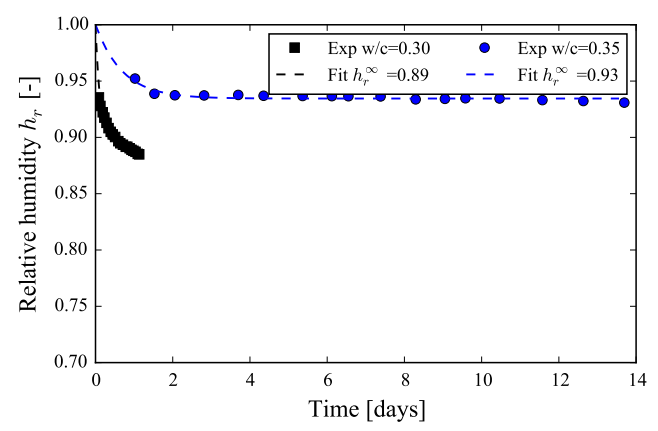

(a)

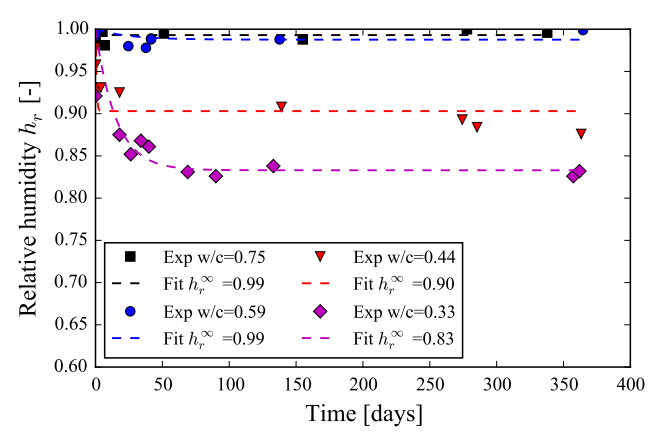

(c)

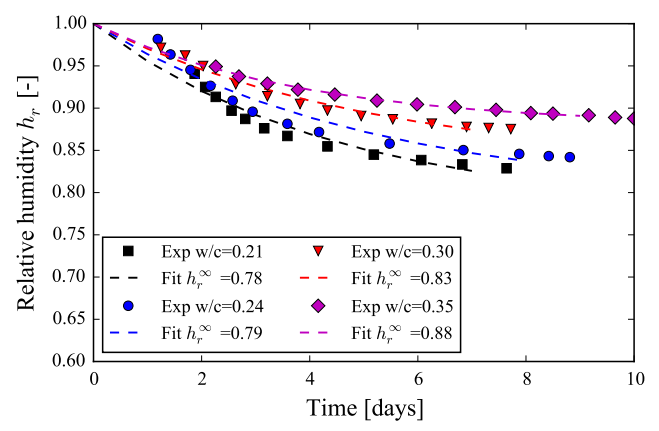

(e)

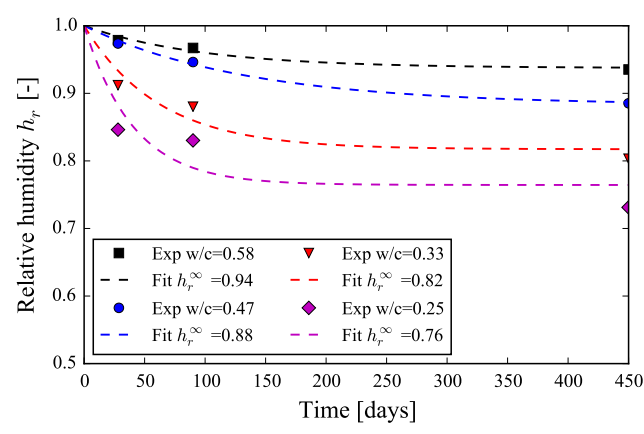

(b)

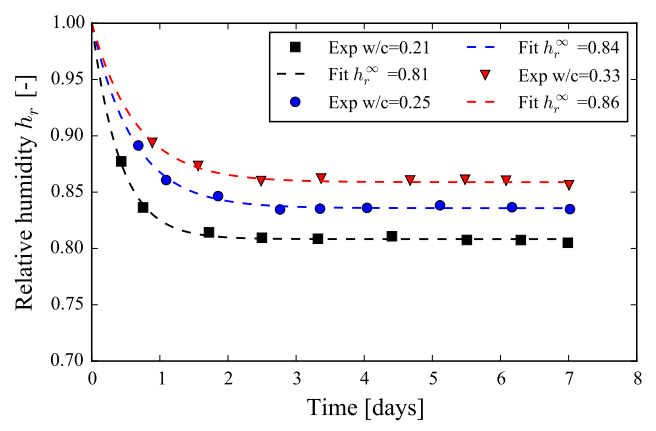

(d)

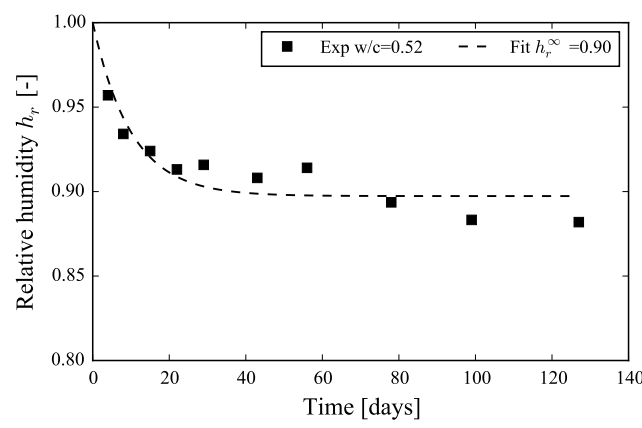

(f)

Figure C.8: Evolution of relative humidity with respect to time under autogenous conditions. Data from (a) [67, 68], (b) [69], (c) [71], (d) [73], (e) [74], (f) $[75]$. 


\section{References}

[1] RILEM Technical Committee, Creep and shrinkage prediction model for analysis and design of concrete structures-model b3, Materials and Structures 28 (1995) 357-365.

[2] F. Benboudjema, F. Meftah, J.-M. Torrenti, A viscoelastic approach for the assessment of the drying shrinkage behaviour of cementitious materials, Materials and Structures 40 (2) (2007) 163-174.

[3] RILEM Technical Committee, RILEM draft recommendation: TC-242MDC multi-decade creep and shrinkage of concrete: material model and structural analysis, Materials and Structures 48 (4) (2015) 753770. doi:10.1617/s11527-014-0485-2.

URL http://link.springer.com/10.1617/s11527-014-0485-2

[4] E. 1992-1-1:2005, Eurocode 2: Design of Concrete Structures: Part 1-1: General Rules and Rules for Buildings, CEN, 2004.

[5] ACI Committee 209, Guide for Modeling and Calculating Shrinkage and Creep in Hardened Concrete (ACI 209.2R-08), American Concrete Institute, 2008.

[6] FIB, Model code for concrete structures 2010, Ernst and Son.

[7] F. De Larrard, Creep and shrinkage of high-strength field concretes, Special Publication 121 (1990) 577-598. 
[8] K. S. Gopalakrishnan, Creep of concrete under multiaxial compressive stresses, Ph.D. thesis, Civil Engineering, University of Calgary (1968). URL http://dhl.handle.net/1880/1815

[9] Z. P. Bazant, M. H. Hubler, Q. Yu, Pervasiveness of excessive segmental bridge deflections: Wake-up call for creep, ACI Structural Journal 108 (6) (2011) 766-774.

[10] R. Le Roy, Déformations instantanées et différées des bétons à hautes performances, Ph.D. thesis, École Nationale des Ponts et Chaussées (1995).

[11] R. Le Roy, F. Le Maou, J.-M. Torrenti, Long term basic creep behavior of high performance concrete: data and modelling, Materials and Structures 50 (1) (2017) 85 .

[12] J.-M. Torrenti, R. Le Roy, Analysis of some basic creep tests on concrete and their implications for modeling, Structural Concrete 0 (2017) 1-6.

[13] A. Aili, M. Vandamme, J.-M. Torrenti, B. Masson, J. Sanahuja, Time evolutions of non-aging viscoelastic poisson's ratio of concrete and implications for creep of c-s-h, Cement and Concrete Research 90 (2016) 144 - 161. doi:http://dx.doi.org/10.1016/j.cemconres.2016.09.014. URL http://www.sciencedirect.com/science/article/pii/S0008884616303544

[14] Q. Zhang, R. L. Roy, M. Vandamme, B. Zuber, Long-term creep properties of cementitious materials: Comparing mi- 
croindentation testing with macroscopic uniaxial compressive testing, Cement and Concrete Research 58 (2014) 89 - 98. doi:http://dx.doi.org/10.1016/j.cemconres.2014.01.004. URL http://www.sciencedirect.com/science/article/pii/S0008884614000052

[15] J. Frech-Baronet, L. Sorelli, J.-P. Charron, New evidences on the effect of the internal relative humidity on the creep and relaxation behaviour of a cement paste by micro-indentation techniques, Cement and Concrete Research 91 (2017) 39-51.

[16] M. Vandamme, F.-J. Ulm, Nanoindentation investigation of creep properties of calcium silicate hydrates, Cement and Concrete Research 52 (2013) 38 - 52. doi:http://dx.doi.org/10.1016/j.cemconres.2013.05.006.

URL http://www.sciencedirect.com/science/article/pii/S0008884613001191

[17] M. Mazloom, A. Ramezanianpour, J. Brooks, Effect of silica fume on mechanical properties of high-strength concrete, Cement and Concrete Composites 26 (4) (2004) 347-357.

[18] J. Brooks, P. Wainwright, Properties of ultra-high-strength concrete containing a superplasticizer, Magazine of Concrete Research 35 (125) (1983) 205-213.

[19] J. Brooks, Accuracy of estimating long-term strains in concrete, Magazine of Concrete Research 36 (128) (1984) 131-145. 
[20] C. Hua, P. Acker, A. Ehrlacher, Analyses and models of the autogenous shrinkage of hardening cement paste: I. modelling at macroscopic scale, Cement and Concrete Research 25 (7) (1995) 1457-1468.

[21] P. Lura, O. M. Jensen, K. van Breugel, Autogenous shrinkage in highperformance cement paste: an evaluation of basic mechanisms, Cement and Concrete Research 33 (2) (2003) 223-232.

[22] D. Gawin, F. Pesavento, B. A. Schrefler, Hygro-thermo-chemomechanical modelling of concrete at early ages and beyond. part ii: shrinkage and creep of concrete, International Journal for Numerical Methods in Engineering 67 (3) (2006) 332-363.

[23] F. Lin, C. Meyer, Modeling shrinkage of portland cement paste, ACI materials journal 105 (3) (2008) 302-311.

[24] L. Stefan, F. Benboudjema, J.-M. Torrenti, B. Bissonnette, Behavior of concrete at early stage using percolation and biot's theory, in: Proceedings of the 4th Biot conference on Poromechanics, 2009.

[25] Z. C. Grasley, C. K. Leung, Desiccation shrinkage of cementitious materials as an aging, poroviscoelastic response, Cement and Concrete Research 41 (1) (2011) 77-89.

[26] M. Wyrzykowski, P. Lura, F. Pesavento, D. Gawin, Modeling of internal curing in maturing mortar, Cement and Concrete Research 41 (12) (2011) 1349-1356. 
[27] J. Zhang, D. Hou, Y. Han, Micromechanical modeling on autogenous and drying shrinkages of concrete, Construction and Building Materials 29 (2012) 230-240.

[28] Y. Luan, T. Ishida, C.-H. Li, Y. Fujikura, H. Oshita, T. I. T. Nawa, T. Sagawa, Enhanced shrinkage model based on early age hydration and moisture status in pore structure, Journal of Advanced Concrete Technology 11 (12) (2013) 1-13.

[29] F.-J. Ulm, R. J. Pellenq, Shrinkage due to colloidal force interactions, in: CONCREEP 10, 2015, pp. 13-16.

[30] M. Abuhaikal, Expansion and shrinkage of early age cementitious materials under saturated conditions: the role of colloidal eigenstresses, Ph.D. thesis, Massachusetts Institute of Technology (2016).

[31] M. Abuhaikal, K. Ioannidou, T. Petersen, R. J.-M. Pellenq, F.-J. Ulm, Le châteliers conjecture: Measurement of colloidal eigenstresses in chemically reactive materials, Journal of the Mechanics and Physics of Solids.

[32] A. Hajibabaee, Z. Grasley, M. Ley, Mechanisms of dimensional instability caused by differential drying in wet cured cement paste, Cement and Concrete Research 79 (2016) 151-158.

[33] X. Li, Z. C. Grasley, J. W. Bullard, E. J. Garboczi, Irreversible desiccation shrinkage of cement paste caused by cement grain dissolution and hydrate precipitation, Materials and Structures 50 (2) (2017) 104. 
[34] Z. P. Bažant, G.-H. Li, Comprehensive database on concrete creep and shrinkage, ACI Materials Journal 105 (6) (2008) 635-637.

[35] S. Shritharan, Structural effects of creep and shrinkage on concrete structures, Master's thesis, University Auckland (1989).

[36] M. Vandamme, F.-J. Ulm, Nanogranular origin of concrete creep, Proceedings of the National Academy of Sciences 106 (26) (2009) 10552 10557.

[37] R. Christensen, Theory of viscoelasticity: an introduction, Elsevier, 1982.

[38] T. Mori, K. Tanaka, Average stress in matrix and average elastic energy of materials with misfitting inclusions, Acta metallurgica 21 (5) (1973) $571-574$.

[39] A. Zaoui, Matériaux hétérogènes et composites: Majeure de Mécanique, option" matériaux et structures, École polytechnique, département de mécanique, 1999.

[40] O. Bernard, F.-J. Ulm, E. Lemarchand, A multiscale micromechanicshydration model for the early-age elastic properties of cement-based materials, Cement and Concrete Research 33 (9) (2003) 1293 - 1309. doi:http://dx.doi.org/10.1016/S0008-8846(03)00039-5. URL http://www.sciencedirect.com/science/article/pii/S0008884603000395 
[41] C. Pichler, R. Lackner, H. A. Mang, A multiscale micromechanics model for the autogenous-shrinkage deformation of early-age cement-based materials, Engineering fracture mechanics 74 (1) (2007) 34-58.

[42] J. Sanahuja, L. Dormieux, G. Chanvillard, Modelling elasticity of a hydrating cement paste, Cement and Concrete Research 37 (10) (2007) 1427 - 1439. doi:http://dx.doi.org/10.1016/j.cemconres.2007.07.003. URL http://www.sciencedirect.com/science/article/pii/S0008884607001548

[43] B. Pichler, C. Hellmich, Upscaling quasi-brittle strength of cement paste and mortar: A multi-scale engineering mechanics model, Cement and Concrete Research 41 (5) (2011) 467 - 476. doi:http://dx.doi.org/10.1016/j.cemconres.2011.01.010. URL http://www.sciencedirect.com/science/article/pii/S0008884611000111

[44] I. Sevostianov, M. Kachanov, On some controversial issues in effective field approaches to the problem of the overall elastic properties, Mechanics of Materials 69 (1) (2014) 93-105.

[45] G. Auliac, J. Avignant, É. Azoulay, Techniques mathématiques pour la physique, Ellipses, 2000.

[46] T. C. Powers, T. L. Brownyard, Studies of the hardened paste by means of specific-volume measurements, Portland Cement Association Bulletin (1947) 669-712.

[47] H. F. Taylor, Cement chemistry, Thomas Telford, 1997. 
[48] V. Waller, Relations entre composition des bétons, exothermique en cours de prise et résistance en compression, Ph.D. thesis, Ecole Nationale des Ponts et Chaussées (1999).

[49] P. K. Mehta, P. J. Monteiro, Concrete: microstructure, properties, and materials, 3rd Edition, McGraw-Hill New York, 2006.

[50] Q. Zhang, Creep properties of cementitious materials : effect of water and microstructure : An approach by microindentation, Ph.D. thesis, Université Paris-Est (2014).

[51] J. Hanson, A ten-year study of creep properties of concrete, Tech. Rep. No. SP-38, Concrete Laboratory, US Department of the Interior, Bureau of Reclamation, Denver (1953).

[52] R. Browne, Properties of concrete in reactor vessels, in: Conference on Prestressed Concrete Pressure Vessels, Group C Institution of Civil Engineers, London,1967, pp. 11-31.

[53] F. Rostasy, T. K.Th., H. Engelke, Beitrag zur klarung des zussammenhanges von kriechen und relaxation bei normal-beton, Tech. Rep. Heft 139, mtliche Forschungs-und Materialpr Aufungsanstalt fur das Bauwesen (1973).

[54] G. Kommendant, M. Polivka, D. Pirtz, Study of concrete properties for prestressed concrete reactor vessels, Tech. Rep. No. UCSESM 76- 
3, Department of Civil Engineering, University of California, Berkeley (1976).

[55] H. Takahashi, T. Kawaguchi, Study on time-dependent behavior of high strength concrete (part 1) - application of the time - dependent linear viscoelasticity theory of concrete creep behavior, Tech. Rep. No.21, Ohbayashi-Gumi Research Institute (1980).

[56] M. Kawasumi, K. Kasahara, T. Kuriyama, Creep of concrete at elevated temperatures, part 3, the influence of ages at loading and water/cement ratios, Tech. Rep. CRIEPI Report, No.382008 (1982).

[57] A. H. Bryant, C. Vadhanavikkit, Creep, shrinkage-size, and age at loading effects, Materials Journal 84 (2) (1987) 117-123.

[58] F. De Larrard, Formulation et propriétés des bétons à très hautes performances, Ph.D. thesis, École Nationale des Ponts et Chaussées (1988).

[59] C. Mazzotti, M. Savoia, C. Ceccoli, A comparison between long-term properties of self-compacting concretes and normal vibrated concretes with same strength, in: Proceedings of the International Conference on Creep, Shrinkage and Durability of Concrete and Concrete Structures, Nantes, France, 2005, pp. 523-528.

[60] R. Mu, J. Forth, A. Beeby, Designing concrete with special shrinkage and creep requirements, in: Proceedings of 8th International Conference on 
Creep, Shrinkage and Durability of Concrete and Concrete Structures, Ise-Shima, Japan, 2009.

[61] L. Dormieux, D. Kondo, F.-J. Ulm, Microporomechanics, John Wiley \& Sons, 2006.

[62] O. Coussy, Mechanics and physics of porous solids, John Wiley \& Sons, 2011.

[63] O. M. Jensen, Thermodynamic limitation of self-desiccation, Cement and Concrete Research 25 (1) (1995) 157-164.

[64] T. C. Powers, A discussion of cement hydration in relation to the curing of concrete, in: Highway Research Board Proceedings, Vol. 27, 1948.

[65] R. J. Flatt, G. W. Scherer, J. W. Bullard, Why alite stops hydrating below $80 \%$ relative humidity, Cement and Concrete Research 41 (9) (2011) 987-992.

[66] V. Baroghel-Bouny, Caractérisation des pâtes de ciment et des bétonsméthodes, analyse, interprétations, Ph.D. thesis, École Nationale des Ponts et Chaussées (1994).

[67] O. M. Jensen, P. F. Hansen, Autogenous deformation and change of the relative humidity in silica fume-modified cement paste, ACI Materials Journal 93 (6) (1996) 539-543. 
[68] O. M. Jensen, P. F. Hansen, Influence of temperature on autogenous deformation and relative humidity change in hardening cement paste, Cement and Concrete Research 29 (4) (1999) 567-575.

[69] B. Persson, Moisture in concrete subjected to different kinds of curing, Materials and Structures 30 (9) (1997) 533-544.

[70] J.-K. Kim, C.-S. Lee, Moisture diffusion of concrete considering selfdesiccation at early ages, Cement and Concrete Research 29 (12) (1999) 1921-1927.

[71] M. P. Yssorche-Cubaynes, J. Ollivier, La microfissuration d'autodessiccation et la durabilité des bhp et bthp, Materials and Structures 32 (1) (1999) 14-21.

[72] Z. Jiang, Z. Sun, P. Wang, Autogenous relative humidity change and autogenous shrinkage of high-performance cement pastes, Cement and Concrete Research 35 (8) (2005) 1539-1545.

[73] S. Zhutovsky, K. Kovler, Hydration kinetics of high-performance cementitious systems under different curing conditions, Materials and structures 46 (10) (2013) 1599-1611.

[74] M. Wyrzykowski, P. Lura, Effect of relative humidity decrease due to self-desiccation on the hydration kinetics of cement, Cement and Concrete Research 85 (2016) 75-81. 
[75] A. Aili, Shrinkage and creep of cement-based materials under multiaxial load: poromechanical modeling for application in nuclear industry, Ph.D. thesis, Université Paris-Est (2017).

[76] H. Köhler, The nucleus in and the growth of hygroscopic droplets, Transactions of the Faraday Society 32 (1936) 1152-1161.

[77] Q. Yang, Inner relative humidity and degree of saturation in highperformance concrete stored in water or salt solution for 2 years, Cement and Concrete Research 29 (1) (1999) 45-53.

[78] Q.-b. Yang, S.-q. Zhang, Self-desiccation mechanism of highperformance concrete, Journal of Zhejiang University-Science A 5 (12) (2004) 1517-1523.

[79] H. Chen, M. Wyrzykowski, K. Scrivener, P. Lura, Prediction of selfdesiccation in low water-to-cement ratio pastes based on pore structure evolution, Cement and concrete research 49 (2013) 38-47.

[80] Z. Hu, Prediction of autogenous shrinkage in fly ash blended cement systems, Ph.D. thesis, École Polytechnique Fédérale de Lausanne (2017).

[81] H. M. Jennings, A model for the microstructure of calcium silicate hydrate in cement paste, Cement and Concrete Research 30 (1) (2000) 101 - 116. doi:http://dx.doi.org/10.1016/S0008-8846(99)00209-4. URL http://www.sciencedirect.com/science/article/pii/S0008884699002094 
[82] S. Ghabezloo, Association of macroscopic laboratory testing and micromechanics modelling for the evaluation of the poroelastic parameters of a hardened cement paste, Cement and Concrete research 40 (8) (2010) 1197-1210.

[83] F.-J. Ulm, A. Delafargue, G. Constantinides, Experimental microporomechanics, in: Applied micromechanics of porous materials, Springer, 2005, pp. 207-288.

[84] B. Pichler, L. Dormieux, Consistency of homogenization schemes in linear poroelasticity, Comptes Rendus Mecanique 336 (8) (2008) 636-642.

[85] B. Pichler, C. Hellmich, Estimation of influence tensors for eigenstressed multiphase elastic media with nonaligned inclusion phases of arbitrary ellipsoidal shape, Journal of engineering mechanics 136 (8) (2010) 10431053.

[86] O. Coussy, S. Brisard, Prediction of drying shrinkage beyond the pore isodeformation assumption, Journal of Mechanics of Materials and structures 4 (2) (2009) 263-279.

[87] E. Tazawa, S. Miyazawa, Autogenous shrinkage of concrete and its importance in concrete technology, in: Proceedings of 5th International Conference on Creep, Shrinkage and Durability of Concrete and Concrete Structures, Barcelona, Spain, 1993, pp. 159-174. 
[88] E.-i. Tazawa, S. Miyazawa, Influence of cement and admixture on autogenous shrinkage of cement paste, Cement and Concrete Research 25 (2) (1995) 281-287.

[89] W. J. Weiss, B. B. Borichevsky, S. P. Shah, The influence of a shrinkage reducing admixture on early-age shrinkage behavior of high performance concrete, in: 5th International Symposium on Utilization of High Strength/High Performance Concrete, Vol. 2, 1999, pp. 1339-1350.

[90] J. Brooks, M. M. Johari, Effect of metakaolin on creep and shrinkage of concrete, Cement and Concrete Composites 23 (6) (2001) 495-502.

[91] H. Lee, K. Lee, B. Kim, Autogenous shrinkage of high-performance concrete containing fly ash, Magazine of Concrete Research 55 (6) (2003) $507-515$.

[92] M. Zhang, C. Tam, M. Leow, Effect of water-to-cementitious materials ratio and silica fume on the autogenous shrinkage of concrete, Cement and Concrete Research 33 (10) (2003) 1687-1694.

[93] T. Vidal, S. Assié, G. Pons, Creep and shrinkage of self-compacting concrete and comparative study with model code, in: Proceedings of the Seventh International Conference, Ecole Centrale de Nantes, France, 2005, pp. 541-546.

[94] Y. Lee, S.-T. Yi, M.-S. Kim, J.-K. Kim, Evaluation of a basic creep 
model with respect to autogenous shrinkage, Cement and concrete research 36 (7) (2006) 1268-1278.

[95] A. C. Muller, K. L. Scrivener, A. M. Gajewicz, P. J. McDonald, Densification of $\mathrm{c}^{-} \mathrm{s}-\mathrm{h}$ measured by $1 \mathrm{~h}$ nmr relaxometry, The Journal of Physical Chemistry C 117 (1) (2012) 403-412.

[96] A. Muller, K. Scrivener, A. Gajewicz, P. McDonald, Use of bench-top nmr to measure the density, composition and desorption isotherm of $\mathrm{c}^{-}$ $\mathrm{s}-\mathrm{h}$ in cement paste, Microporous and Mesoporous Materials 178 (2013) 99-103.

[97] M. Königsberger, C. Hellmich, B. Pichler, Densification of csh is mainly driven by available precipitation space, as quantified through an analytical cement hydration model based on nmr data, Cement and Concrete Research 88 (2016) 170-183. 